\title{
Macrophages Promote Axon Regeneration with Concurrent Neurotoxicity
}

\author{
John C. Gensel, ${ }^{1}$ Satoshi Nakamura, ${ }^{2}$ Zhen Guan, ${ }^{1}$ Nico van Rooijen, ${ }^{3}$ Daniel P. Ankeny, ${ }^{1}$ and Phillip G. Popovich ${ }^{1}$ \\ ${ }^{1}$ Center for Brain and Spinal Cord Repair, Department of Molecular Virology, Immunology, and Medical Genetics, The Ohio State University College of \\ Medicine, Columbus, Ohio 43210, ${ }^{2}$ Department of Neurosurgery, Tokyo Women's Medical University Medical Center East, Tokyo 116-8567, Japan, and \\ ${ }^{3}$ Department of Molecular Cell Biology, Vrije Universiteit, 1081 BT Amsterdam, The Netherlands
}

Activated macrophages can promote regeneration of CNS axons. However, macrophages also release factors that kill neurons. These opposing functions are likely induced simultaneously but are rarely considered together in the same experimental preparation. A goal of this study was to unequivocally document the concurrent neurotoxic and neuroregenerative potential of activated macrophages. To do so, we quantified the length and magnitude of axon growth from enhanced green fluorescent protein-expressing dorsal root ganglion (DRG) neurons transplanted into the spinal cord in relationship to discrete foci of activated macrophages. Macrophages were activated via intraspinal injections of zymosan, a potent inflammatory stimulus known to increase axon growth and cause neurotoxicity. Using this approach, a significant increase in axon growth up to macrophage foci was evident. Within and adjacent to macrophages, DRG and spinal cord axons were destroyed. Macrophage toxicity became more evident when zymosan was injected closer to DRG soma. Under these conditions, DRG neurons were killed or their ability to extend axons was dramatically impaired. The concurrent induction of proregenerative and neurotoxic functions in zymosan-activated macrophages (ZAMs) was confirmed in vitro using DRG and cortical neurons. Importantly, the ability of ZAMs to stimulate axon growth was transient; prolonged exposure to factors produced by ZAMs enhanced cell death and impaired axon growth in surviving neurons. Lipopolysaccharide, another potent macrophage activator, elicited a florid macrophage response, but without enhancing axon growth or notable toxicity. Together, these data show that a single mode of activation endows macrophages with the ability to simultaneously promote axon regeneration and cell killing.

\section{Introduction}

There is compelling evidence that macrophages derived from microglia and blood monocytes can promote regeneration of CNS axons. However, macrophages also can kill neurons and glia (for review see, Stoll et al., 2002). At first glance, these divergent effects seem mutually exclusive. This perspective is often reinforced when an experimental design seeks to document indices of repair or injury. Rarely are experiments designed to simultaneously document the pro-regenerative and neurotoxic effects of macrophages.

Data from various models suggest that macrophages can elicit injury and repair simultaneously or as part of an activation continuum. For example, in a model of myocardial infarction, injurious functions are attributed to monocytes recruited early, whereas later infiltrating monocytes promote repair (Nahrendorf et al., 2007). In a glioma model, macrophages possessing injury or repair characteristics are simultaneously recruited to the tumor (Umemura et al., 2008). In the CNS, different experimental prep-

Received Aug. 21, 2008; revised Feb. 18, 2009; accepted Feb. 22, 2009.

This work was supported by National Institute of Neurological Disorders and Stroke Grant NS 037846, The Craig H. Neilsen Foundation, and the Paralysis Project of America. We are grateful to Dr. Jerry Silver and Kevin Horn for assistance with the DRG transplantation protocol. We also thank Dr. Dana McTigue for providing editorial feedback and Dr. Richa Tripathi and David Schonberg for discussion about CNTF quantification.

Correspondence should be addressed to Phillip G. Popovich, 786 Biomedical Research Tower, 460 West 12th Avenue, Columbus, 0H 43210. E-mail: Phillip.Popovich@osumc.edu.

DOI:10.1523/JNEUROSCI.3992-08.2009

Copyright $\odot 2009$ Society for Neuroscience $\quad$ 0270-6474/09/293956-13\$15.00/0 arations have reinforced the notion that macrophages exert polarized effects. For example, intraparenchymal injections of zymosan (a yeast cell wall component and potent macrophage stimulus) were used originally to model the injurious effects of macrophages activated by CNS trauma without consideration of their pro-regenerative potential (Fitch et al., 1999; Popovich et al., 2002). Conversely, the Benowitz laboratory showed that zymosan-activated macrophages (ZAMs) promote regeneration of retinal ganglion cell (RGC) axons (Yin et al., 2003). Similarly, ZAMs were shown to promote functionally significant regeneration of injured dorsal root ganglion (DRG) axons (Steinmetz et al., 2005). An important but often overlooked observation in the original report by Yin et al. was that ZAMs also killed a large number of RGCs in vitro. This important observation has been overshadowed by the repair capacity of ZAMs. Indeed, follow-up studies concentrated on identifying only the pro-regenerative molecule(s) released by ZAMs (Yin et al., 2006).

To better understand if a single stimulus can cause macrophages to promote neurotoxicity and regeneration in the CNS, we combined a well established nontraumatic DRG transplantation technique with intraspinal zymosan microinjections (Davies et al., 1997, 1999; Popovich et al., 2002). Because zymosan elicits a pluripotent macrophage response, it is ideal for exploiting the dual nature of macrophage activation. Here, we show that ZAMs modify the surrounding microenvironment and significantly increase axon growth; however, this is accompanied by axon loss and cell death within and nearby activated macrophages. Toxicity 

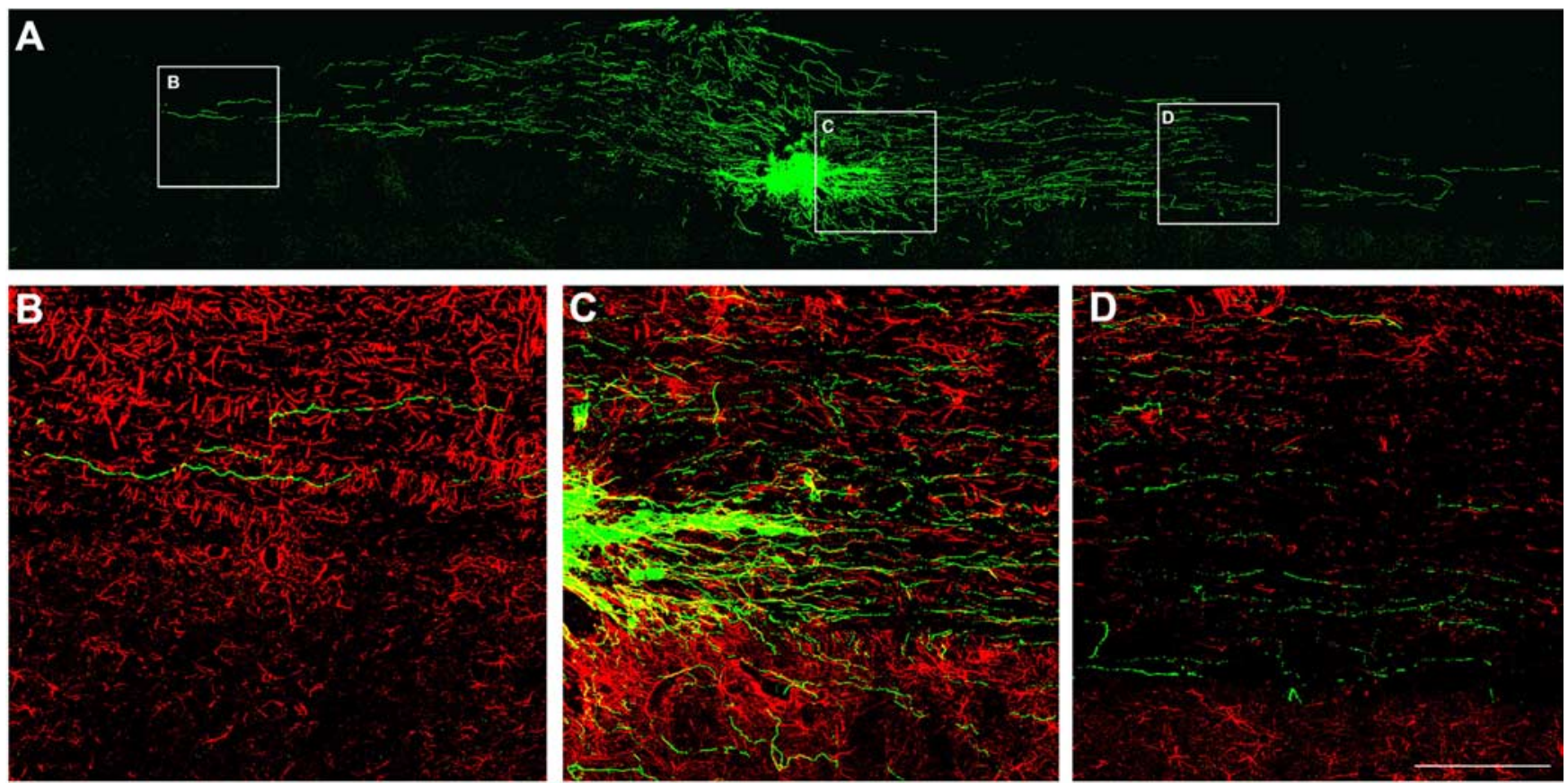

Figure 1. An in vivo model for assessing growth/regeneration of a defined axon population. Adult mouse EGFP + DRG neurons were transplanted into the adult rat cervical (C1/2) spinal cord using the technique described by Davies et al. (1999). Eight days after transplantation, DRG axons extend into the spinal cord rostral and caudal from the injection site. $A, A$ confocal montage of a sagittal section of the spinal cord $8 \mathrm{~d}$ after transplantation. $\boldsymbol{B}-\boldsymbol{D}$, High-power montage of boxed areas in $\boldsymbol{A}$ showing the relationship between GFP + axons (green) and GFAP + astrocytes (red) throughout the rostral ( $\boldsymbol{B}$ ) and caudal (D) axes of the intact spinal cord. Scale bars: $\boldsymbol{A}, 875 \mu \mathrm{m} ; \boldsymbol{B}-\boldsymbol{D}, 200 \mu \mathrm{m}$.
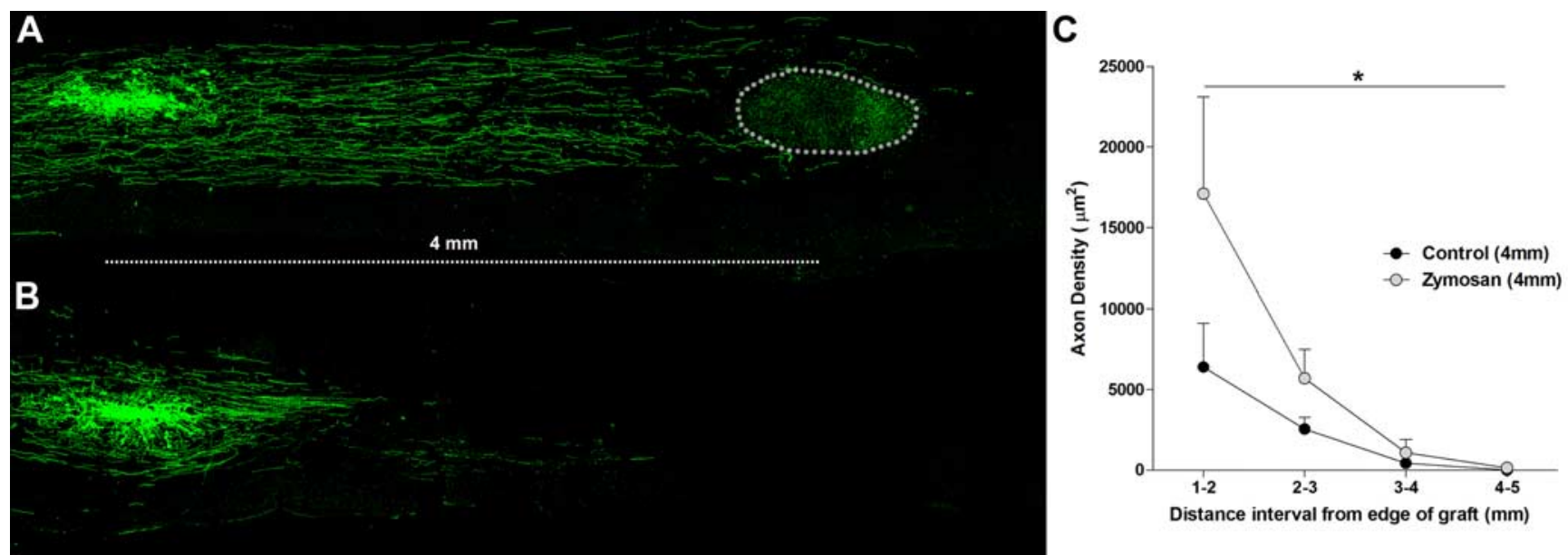

Figure 2. ZAMs promote axon growth in the spinal cord. $A, B$, Confocal montages of GFP + DRG axons growing toward a site of zymosan $(\boldsymbol{A})$ or control $(\boldsymbol{B})$ injection $\sim 4 \mathrm{~mm}$ caudal to the site of DRG transplantation. These images are representative of the average caudal axon growth from each group. Note the significant increase in axon growth toward foci of ZAMs (dotted circle) in $A$. $C$, Quantification of axonal outgrowth from the graft reveals a significant increase in axon growth in spinal cords injected with zymosan. ${ }^{*} p<0.05$ versus controls over the distance measured.

was enhanced, and regeneration was decreased when macrophages were activated closer to the soma of DRG neurons. In vitro, ZAM-derived factors transiently promote DRG axon growth. Ultimately, ZAMs killed most neurons in vitro and in vivo. For those neurons that survived, axon growth/sprouting was reduced. The pro-regenerative and neurotoxic effects of macrophages were stimulus specific. Indeed, lipopolysaccharide (LPS)activated macrophages failed to enhance axon growth and were only mildly neurotoxic. Together, these data show that a single mode of activation endows macrophages with the ability to simultaneously promote axon regeneration and cell killing. Additional work is needed to determine whether these macrophage functions can be modified to selectively enhance only those functions that promote repair.

\section{Materials and Methods}

Dissociation and preparation of DRG cells. Single-cell suspensions of cervical, thoracic, and lumbar DRG neurons were prepared from the spinal cord of anesthetized adult (2-3 months of age) transgenic enhanced green fluorescent protein (EGFP) mice (C57BL/6-Tg(ACTBEGFP)1Osb/J; The Jackson Laboratory) (Lindsay et al., 1991). Dissected DRGs were incubated in dispase $2(5 \mathrm{U} / \mathrm{ml}$; Roche) and collagenase type $2(200 \mathrm{U} / \mathrm{ml}$; Worthington) for $45 \mathrm{~min}$ at room temperature in calcium and magnesium-free HBSS (Mediatech) (Davies et al., 1999). Enzymes were removed, and $250 \mu \mathrm{g} / \mathrm{ml}$ DNasel type 2 (Sigma) was added to the medium for $5 \mathrm{~min}$. DRGs were triturated in $500 \mu \mathrm{l}$ of HBSS medium through Pasteur pipettes and spun at $3000 \mathrm{rpm}$ for $180 \mathrm{~s}$. The neuronenriched pellet was resuspended in 20-70 $\mu$ l of L15 medium (Invitrogen) with $5 \mu \mathrm{g} / \mathrm{ml}$ DNase1 type 2 for an average neuronal density of 680 cells per microliter. 

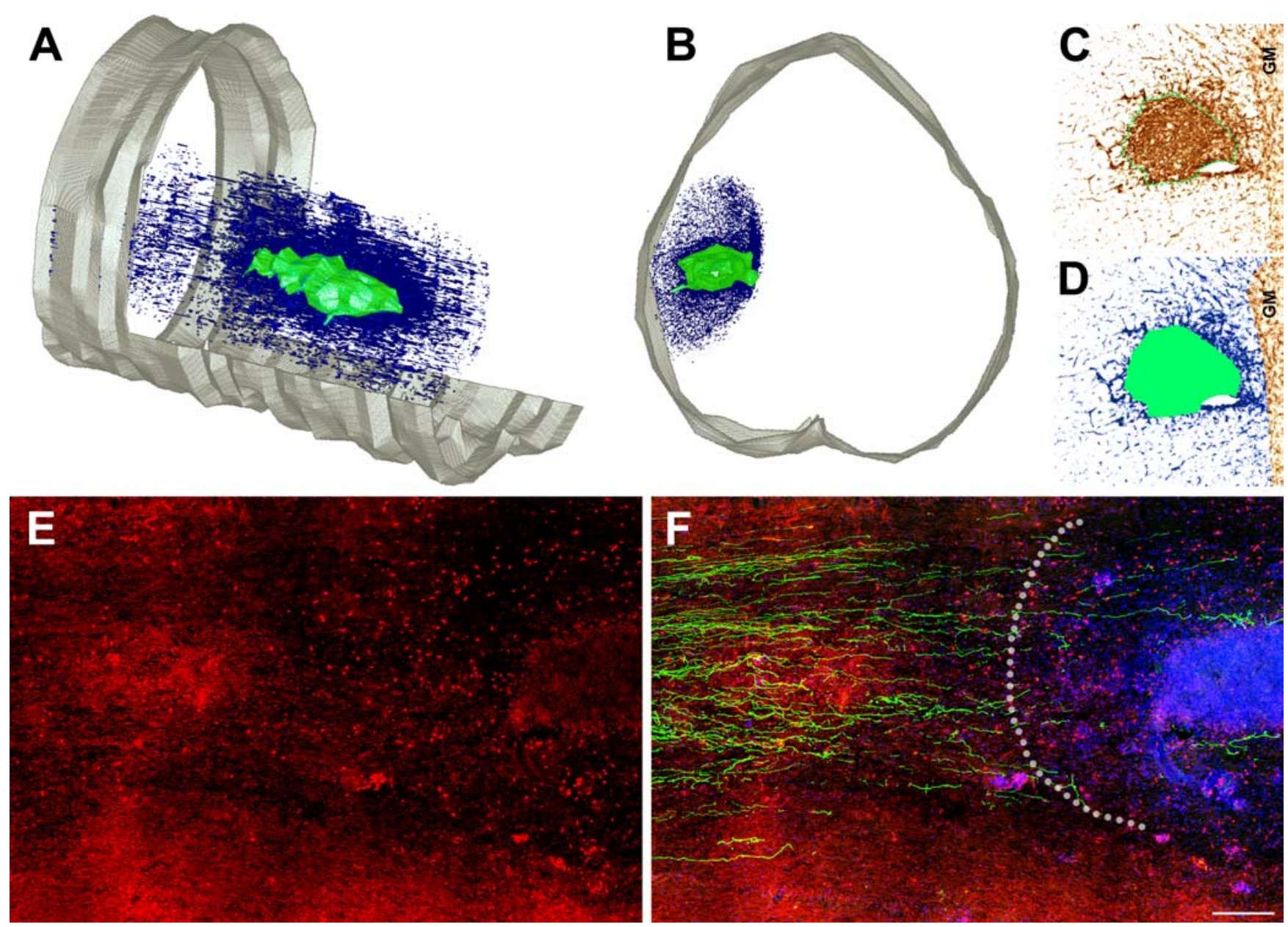

Figure 3. Zymosan-activated macrophages modify the surrounding microenvironment creating passages for axon growth. $A, B, A$ three-dimensional (3D) schematic showing the formation of a graded column of activated microglia and macrophages emanating from a zymosan injection site ( $\boldsymbol{A}, \boldsymbol{B}, \boldsymbol{D}$, green). Phagocytic monocyte-derived macrophages (MDMs) occupy the center of the injection site (see also Fig. 8) (Popovich et al., 2002). Activated microglia (blue) lie adjacent to MDMs and form a column of activated cells that extends for several millimeters. C, D, A two-dimensional representation of spinal cord sections stained for microglia/macrophages ( $0 X 42$ antibody), then rendered in third dimension in $\boldsymbol{A}$ and $\boldsymbol{B}$. Green shading corresponds with the center of the injection site and the area where MDMs infiltrate. These areas were manually outlined for $3 \mathrm{D}$ rendering. Blue shading corresponds with automated threshold scans of $0 X 42+$ microglia in white matter. GM, Gray matter. $E, F$, Graded levels of myelin loss (MBP; red) surround the zymosan injection site. EGFP+DRG axons (green) grow through regions of intact and degenerating myelin into areas occupied by activated microglia. Axon growth is diminished or aborted immediately adjacent to sites of MDM accumulation (dotted line in $\boldsymbol{F}$ ). Scale bar: $A, B, 34 \mu \mathrm{m} ; C, D, 186 \mu \mathrm{m} ; \boldsymbol{E}, \boldsymbol{F}, 200 \mu \mathrm{m}$.

DRG transplantation and intraspinal macrophage activation. Adult female Sprague Dawley rats (200-225 g; Harlan) were anesthetized with subcutaneous ketamine $(80 \mathrm{mg} / \mathrm{kg}$ ) and xylazine $(50 \mathrm{mg} / \mathrm{kg})$. A laminectomy was performed to expose either the cervical or thoracic spinal cord. The C1/2 junction of the cervical spinal cord was exposed, and the dura and pia matter was removed. Animals were secured with spinous process clamps on residual $\mathrm{C} 1$ and $\mathrm{C} 3$ vertebrae, and microinjections were performed via calibrated pressure microinjection (PV800 Pneumatic PicoPump; David Kopf Instruments) using pulled glass micropipettes (PD-5 Micropipette Puller; Narishige). Pipettes were beveled to an external diameter of 30-80 $\mu \mathrm{m}$ (Beveller 1300M-C; World Precision Instruments) and were sterilized overnight under UV light. To target the dorsal column white matter, stereotaxic injections were made $400 \mu \mathrm{m}$ lateral to midline and $600 \mu \mathrm{m}$ deep (Popovich et al., 2002). DRG suspensions (750 nl) were microinjected into the $\mathrm{C} 1 / 2$ junction using a 55 - to $80-\mu \mathrm{m}$ diameter beveled tip glass pipette and were monitored through a microscope to confirm consistent transplant delivery. For data in supplemental Figure 1 (available at www.jneurosci.org as supplemental material), DRG neurons were injected into the C3 cervical spinal cord.

To align transplanted DRGs with regions of macrophage activation caudal to the transplant site, macrophage activating factors were microinjected at the time of DRG transplantation. All injections were positioned $400 \mu \mathrm{m}$ lateral to midline and $600 \mu \mathrm{m}$ deep into the parenchyma. Sham control injections (pipette insertion without injection), or $100 \mathrm{nl}$ of vehicle (saline), zymosan (10 mg/ml; Sigma), or LPS (2 mg/ml, from Escherichia coli 055:B5; Sigma), were delivered 2 or $4 \mathrm{~mm}$ caudal to the injection site using a glass pipette of $30 \mu \mathrm{m}$ (sham, vehicle, LPS) or $50 \mu \mathrm{m}$ (zymosan). A small subset of animals received vehicle or zymosan injections $4 \mathrm{~mm}$ rostral to DRG injections into the $\mathrm{C} 3$ cervical spinal cord. For three-dimensional reconstructions and analysis of macrophage depletion, $50 \mathrm{nl}$ injections of zymosan $(12.5 \mathrm{mg} / \mathrm{ml})$ were delivered $1-1.2 \mathrm{~mm}$ lateral to midline and 500-700 $\mu \mathrm{m}$ deep into the thoracic spinal cord at the T8/T9 vertebral level (Popovich et al., 2002). Intraganglionic injections of zymosan (100 nl) or PBS (50 nl) were made into the L4 or L5 lumbar DRG. The three-dimensional reconstruction of a zymosan injection site (see Fig. 3) was created using the M3D plug-in for the MCID system (InterFocus Imaging). The area containing round, activated OX $42+$ cells was manually outlined on 29 sections spanning $\sim 3 \mathrm{~mm}$ of spinal cord. The density of OX42 immunoreactivity emanating from the center of maximal OX42 labeling was then labeled by densitometric thresholding over the same distance.

Macrophage depletion and analysis of zymosan injection sites. Clodronate (a gift from Roche Diagnostics) was encapsulated in multilamellar liposomes and injected as described previously (van Rooijen and Sanders, 1994; Popovich et al., 1999). Briefly, liposomes or PBS were injected into the tail vein ( $2 \mathrm{ml}$ per injection in PBS) 1,3 , and $6 \mathrm{~d}$ after intraspinal injection of zymosan. Injections were performed under brief inhalation anesthesia with isoflourane. PBS is the proper control for clodronate 

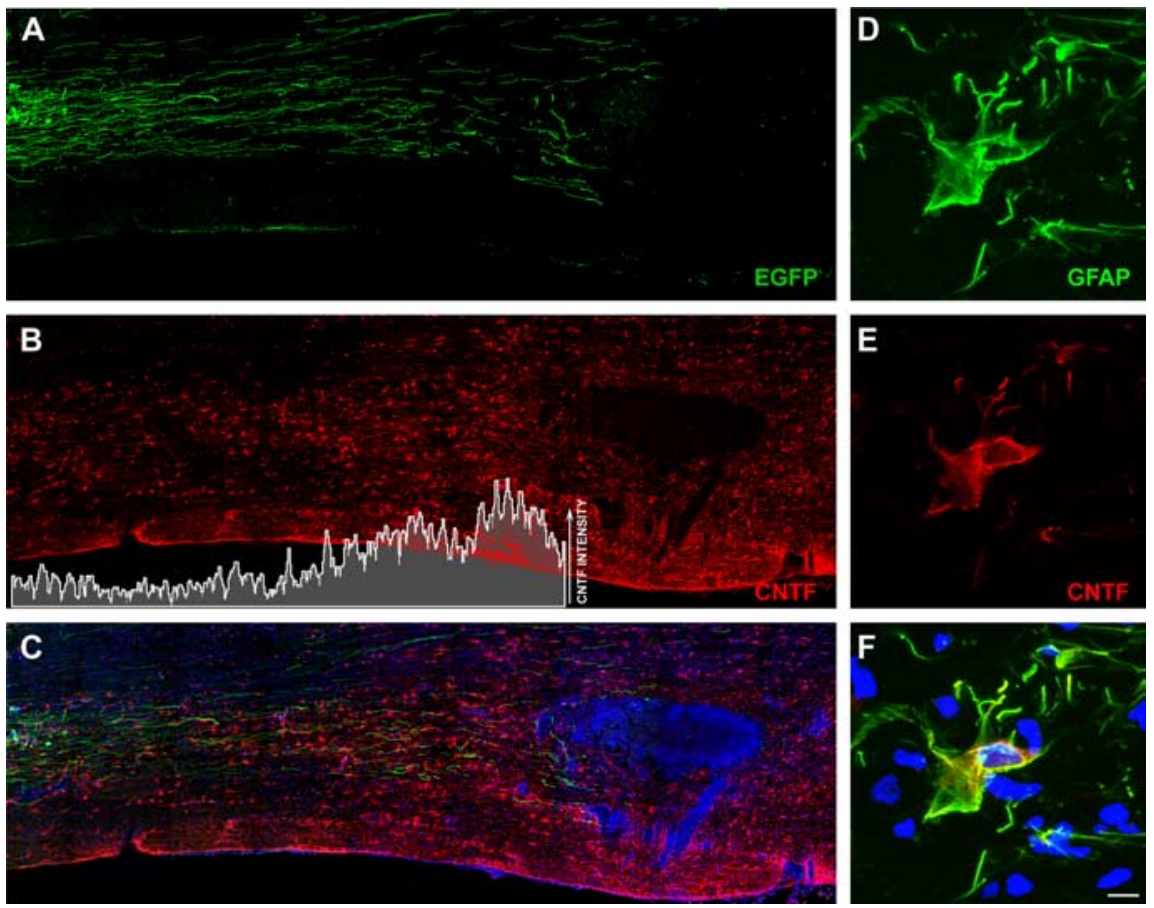

Figure 4. ZAMs induce a gradient of CNTF expression. $\boldsymbol{A}-\boldsymbol{C}$, Parasaggital section of spinal cord transplanted with DRG neurons and injected with zymosan $\sim 4 \mathrm{~mm}$ caudal to the transplant. Individual confocal scans show EGFP + axons $(\boldsymbol{A}$, green) and CNTF immunoreactivity $(\boldsymbol{B}$, red). Merged images show nuclear labeling (DRAQ5; $\boldsymbol{C}$, blue). Note that DRG axons grow toward ZAMs through a dense CNTF + astroglial substrate then stop abruptly at ZAM interface. A linear scan of staining intensity between the DRG transplant site and the core of ZAMs shows an increase in CNTF immunoreactivity closer to the zymosan injection site; CNTF labeling is noticeably absent from the ZAM core. $\boldsymbol{D}-\boldsymbol{F}$, High-powered confocal images show that GFAP + astrocytes $(\boldsymbol{D}$, green $)$ are the predominant source of CNTF ( $\boldsymbol{E}$, red). Merged images show nuclear labeling (DRAQ5; $\boldsymbol{F}$, blue). Scale bar: $\boldsymbol{A}-\boldsymbol{C}, 200 \mu \mathrm{m} ; \boldsymbol{D}-\boldsymbol{F}$, $7.5 \mu \mathrm{m}$.

liposomes because liposome-encapsulated PBS alters the function of healthy macrophages (Popovich et al., 1999; Gray et al., 2007). In Figure 9, zymosan injection sites were identified for each animal by identifying the tissue section containing the largest region of round OX42+ macrophages. Lesion size was determined by manually outlining areas devoid of myelin or axon labeling. The magnitude of macrophage activation was quantified and expressed as the total area of OX42+ immunoreactivity.

Tissue processing and immunohistochemistry. At various times after injection, rats were anesthetized and perfused transcardially with $\sim 200$ $\mathrm{ml}$ of cold $0.1 \mathrm{M}$ PBS and $300 \mathrm{ml}$ of $4 \%$ paraformaldehyde. Spinal cords or DRGs were removed, rinsed in $0.2 \mathrm{M}$ phosphate buffer (PB), and stored overnight. Tissues were cryoprotected by immersing them in increasing concentrations of sucrose (10-30\%) over several days, blocked, embedded in OCT compound, and frozen on dry ice. Frozen spinal cord blocks were sectioned on a cryostat at $30 \mu \mathrm{m}$ in the parasagittal plane (aligned parallel to the central canal) or at $10 \mu \mathrm{m}$ in the transverse plane (frontal). Sequential sections were collected on Superfrost Plus slides (Thermo Fisher Scientific). For immunohistochemical labeling, sections were washed in $0.5 \mathrm{M}$ Tris buffer (TB), permeablized with $1.0 \%$ Triton X-100/ $0.2 \mathrm{M} \mathrm{PB}$, and incubated overnight with primary antibodies prepared in blocking solution. Secondary and tertiary steps for single, double, and triple staining were performed using standard immunocytochemical methods. Antibodies against GFP (1:800; rabbit; Invitrogen) were used to label transplanted DRG neurons. Primary monoclonal antibodies were used to label astrocytes [glial fibrillary acidic protein (GFAP); 1:1000; rabbit; Dako Denmark], microglia/macrophages (OX42; 1:500; mouse, AbD; Serotec), ciliary neurotrophic factor (CNTF; 1:800; goat; R \& D Systems), or myelin basic protein (SMI-94; 1:20,000; Sternberger Monoclonals). Biotin-conjugated lectin from Wisteria floribunda agglutinin (WFA; $15 \mu \mathrm{g} / \mathrm{ml}$; Sigma) was used to label chodroitin sulfate proteogylcans (CSPG) (Bruckner et al., 1998). Alexa Fluor 488 (AF488)-, AF546-, or AF633 (1:1000)-conjugated secondary antibodies were used to visualize primary antibody labeling. DRAQ5 (1:3000; Biostatus Lim- ited) or DAPI (4',6-diamidino-2-phenylindole; Sigma) was added to secondary antibodies to label cell nuclei. Fluoromyelin (Invitrogen) was used according to the manufacturer's specifications to label myelin. A subset of sections was stained for macrophages/microglia (OX42; 1:4000; mouse, AbD; Serotec), GFP (1:800; rabbit; Invitrogen), or axons (NF200; 1:5000; rabbit; Millipore Bioscience Research Reagents) using peroxidase-based immunohistochemistry or eriochrome cyanine and cresyl violet, for myelin and cell nuclei, respectively.

Analysis of axon length. For analysis of DRG axon growth, serial sections were analyzed through the width of the DRG transplant site. Cases in which activated macrophage foci were $>500 \mu \mathrm{m}$ from their intended location (2 or 4 $\mathrm{mm}$ caudal to the DRG transplant) and/or transplants did not extend axons into the spinal cord parenchyma ( $2 \mathrm{~mm}$ of zymosan; see Results) were excluded. Because no significant differences in DRG axon growth were detected between groups receiving sham or vehicle control injections, whether injected 2 or $4 \mathrm{~mm}$ caudal to the DRG transplant, the groups were collapsed for analyses. Final numbers for each group were as follows: control (for zymosan), $n=9 ; 4 \mathrm{~mm}$ of zymosan, $n=5 ; 2$ mm of zymosan, $n=12$; control (for LPS), $n=8 ; 4 \mathrm{~mm}$ of LPS, $n=5 ; 2$ $\mathrm{mm}$ of LPS, $n=3$. The maximum distances reached by DRG axons from the center of the DRG transplant (rostral and caudal) were quantified using an Axioplan 2 imaging microscope (Zeiss) with a motorized $X-Y$ stage controlled by MCID image quantification software. The density of DRG axon growth was determined for each animal in sections containing the largest DRG transplant (as determined by GFP + labeling). Total axon density was estimated in regular intervals from the edge of the transplantation site to the point of the longest axon by quantifying the area of GFP labeling above threshold in a standardized sample box (1 $\mathrm{mm}^{2}$ ).

The MCID software was used to detect and enumerate cresyl violetstained DRG neuronal profiles at sites of intraganglionic zymosan injections (see Fig. 8). A MetaMorph image analysis system (Molecular Devices) was used to analyze the gradient intensity of CNTF labeling across an arbitrary sample line extending from the site of DRG transplantation to the area of macrophage activation (see Fig. 4).

Macrophage-conditioned medium. Bone marrow-derived macrophages were obtained from adult C57BL/6 mice as described previously (Longbrake et al., 2007). After 6 d in culture, macrophages were removed from flasks using a cell scraper and resuspended in Neurobasal A (NBA) medium supplemented with 2\% B27, 1\% Glutamax, and 1\% penicillinstreptomycin. Cells were replated in six-well plates at $10 \times 10^{6}$ cells/well. The following day, medium was replaced with NBA containing zymosan $(1.25 \mathrm{mg} / \mathrm{ml})$, LPS $(100 \mathrm{ng} / \mathrm{ml})$, or fresh NBA. Macrophages were activated for $8 \mathrm{~h}$ at $37^{\circ} \mathrm{C}$ in $5 \% \mathrm{CO}_{2}$, after which the macrophageconditioned medium (MCM) was collected, centrifuged (1200 rpm, 5 $\mathrm{min})$, and filtered (0.22 $\mu \mathrm{m}$ low-protein binding filter; Millipore) to remove the zymosan particles, LPS, and cell debris. All MCMs were stored at $-20^{\circ} \mathrm{C}$.

In vitro analysis of DRG neurons. Suspensions of DRG neurons were prepared as described above. Neurons were suspended in NBA medium with supplements (see above) and plated onto coverslips at 500 cells/ coverslip. All coverslips were precoated with $0.1 \mathrm{mg} / \mathrm{ml}$ poly-L-lysine (Sigma) and $10 \mu \mathrm{g} / \mathrm{ml}$ laminin (Roche). All medium components were obtained from Invitrogen. Three to four days after plating DRG neurons, $50 \%$ of the medium was removed and replaced with MCM as described above. DRG neurons were incubated with MCM for 24 or $48 \mathrm{~h}$. Cells were 
then washed with $0.1 \mathrm{~m}$ PBS and fixed with $2 \%$ paraformaldehyde for $30 \mathrm{~min}$. A monoclonal anti- $\beta$-tubulin III antibody was used to label DRG neurons (1:2000; Sigma). AF546conjugated secondary antibodies $(1: 1000)$ were used to detect labeled DRG neurons. Four to six coverslips were generated for each experimental condition. At least three independent experiments were conducted for each in vitro manipulation.

MCM effects on DRG survival were determined by performing unbiased counts of the number of $\beta$-tubulin III + cells that remained on each coverslip after 24 or $48 \mathrm{~h}$ of stimulation. Briefly, $45 \%$ of each coverslip was randomly sampled ( $\sim 125$ fields per coverslip) using the stereology feature of the MCID image analysis software. A cell was counted as an intact DRG neuron if it had neuronal morphology, extended at least one process, and had no dystrophic axons. To quantify axon growth, 10 cells per coverslip (40 total cells per condition) were randomly selected for analysis. Only cells with isolated processes that did not contact other cells or cell processes were quantified. To reduce human bias, an automated Sholl (1953) analysis program was developed using the MetaMorph image analysis system. Templates of concentric circles of $50 \mu \mathrm{m}$ intervals were overlaid onto the center of a digitized DRG soma. For each neuron, densitometric thresholds were set to remove background labeling and identify detailed cellular processes. Single pixels of immunoreactive labeling above the threshold of detection were removed to reduce false positives. The total number of objects above threshold intersecting each circle was tallied using an automated macro. The maximal ring with an intersecting process (maximum distance) and sum of the number of intersections (branching complexity) for all rings were generated for each cell and compared among groups.

Cortical neuron toxicity assays. Cortical neuron suspensions were prepared from 2-3 d postnatal mouse pups. After decapitation, the cortex was dissected, minced, and placed in 1.5 $\mathrm{mg}$ of papain prepared in $4 \mathrm{ml}$ of L15/BSA. Solutions were rotated at $100 \mathrm{rpm}$ for $15 \mathrm{~min}$ at $37^{\circ} \mathrm{C}$. After settling, tissues were repeatedly washed in NBA and triturated using pipettes of increasingly smaller diameter. Cells were centrifuged in NBA/B27 medium containing 25\% serum for $6 \mathrm{~min}$ at $1200 \mathrm{rpm}$. Supernatants were discarded, and cells were resuspended in fresh NBA/B27. Cortical neurons were plated in 96-well plates at a density of 30,000 cells/well. The medium was changed every 3-4 d. Seven to ten days after plating, $50 \%$ of the medium was exchanged with fresh medium: MCM prepared as described above or $100 \mu \mathrm{M}$ glutamate (prepared in NBA/B27). Cortical neurons were stimulated for $24 \mathrm{~h}$, washed with $0.1 \mathrm{M} \mathrm{PB}$, and fixed with $2 \%$ paraformaldehyde for $30 \mathrm{~min}$. For each experiment, six replicate wells per condition were prepared.

Cortical neuron survival was assessed using an ELISA-based assay as described previously (Mallat and Chamak, 1994; Brooke et al., 1999). After fixing, cells were washed twice with $0.1 \mathrm{M}$ PBS and then twice with $0.1 \mathrm{M}$ PBS/0.1\% Triton X-100. Washed cells were then incubated for $1 \mathrm{~h}$ at $60 \mathrm{rpm}$ in $10 \% \mathrm{FBS} / 0.1 \mathrm{~m} \mathrm{PBS} / 0.1 \%$ Triton X-100. After this blocking step, anti-MAP2 antibodies (mouse anti-SMI-52; 1:1000 prepared in blocking solution; Covance) were added to each well overnight at $4^{\circ} \mathrm{C}$.
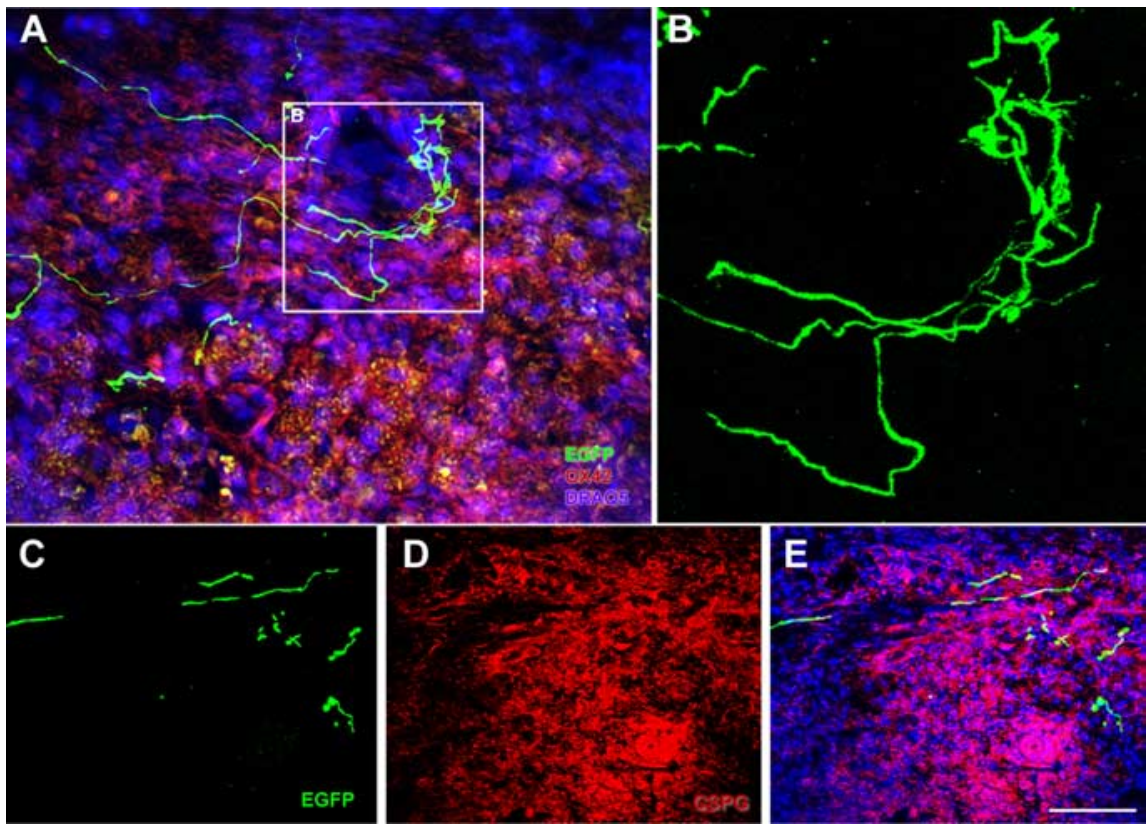

Figure 5. Abortive axon growth occurs at the border of ZAMs. $A, B$, EGFP + axons (green) stop growing or turn as they approach or enter ZAM foci (OX42; red). Note the phagocytic inclusions of GFP remnants (appear yellow) in ZAM (see also Fig. 6). $B$ is a higher-power image of the box in $A$. $C-E$, Abortive axon growth at the ZAM interface colocalizes with dense accumulation (WFA; $\boldsymbol{D}, \boldsymbol{E}$, red). All nuclei are stained with DRAQ5 (blue). Scale bar: $\boldsymbol{A}, 875 \mu \mathrm{m} ; \boldsymbol{B}, 350 \mu \mathrm{m} ; \boldsymbol{C}-\boldsymbol{E}, 100 \mu \mathrm{m}$.
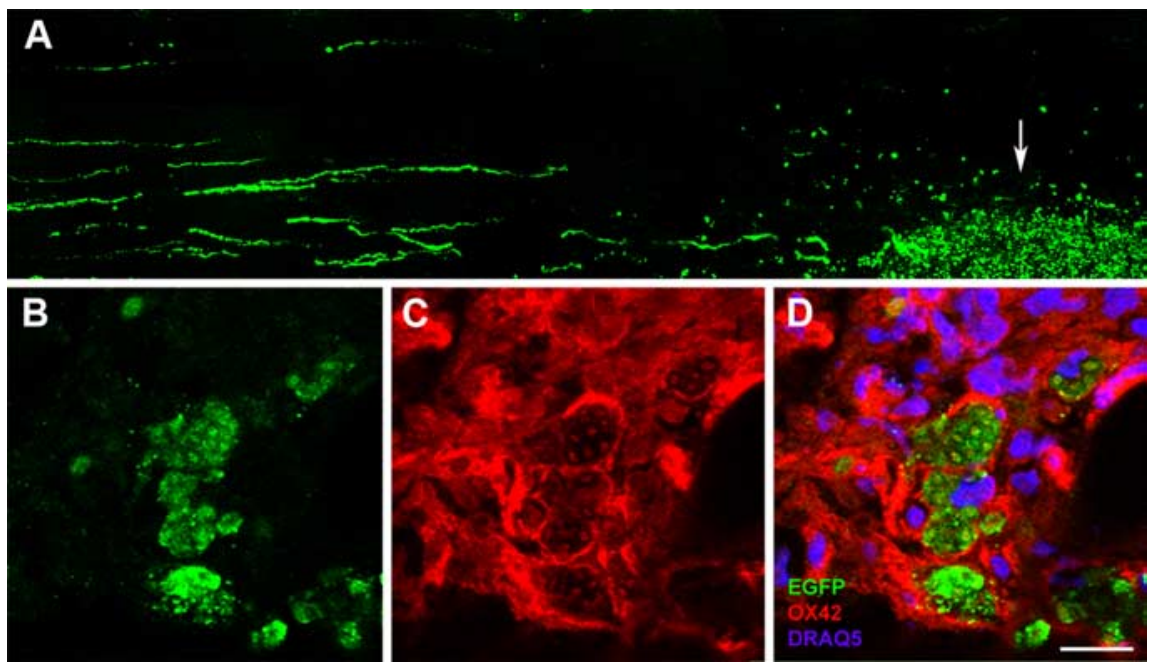

Figure 6. Fragments of growing or degenerating DRG axons are engulfed as they enter areas containing ZAMs. $\boldsymbol{A}$, EGFP+ axons grow toward ZAM foci, then turn (see also Fig. 5) or become fragmented (die back). EGFP + inclusions are evident within macrophages (arrow). $\boldsymbol{B}-\boldsymbol{D}$, High-power Z-stack of EGFP + DRG axon fragments (green) engulfed by 0X42+ macrophages (red). Scale bar: $\boldsymbol{A}, 125 \mu \mathrm{m} ; \boldsymbol{B}-\boldsymbol{D}, 12 \mu \mathrm{m}$.

The next day, cells were washed three times and incubated with biotinylated goat anti-mouse IgG1-alkaline phosphatase (1:1000 in blocking solution; Southern Biotechnology) for $2 \mathrm{~h}$ at room temperature. Cells were washed a final time, this time substituting $0.5 \mathrm{M} \mathrm{TB}$ for PBS, and incubated in pNPP phosphatase substrate. The 96-well plate was inserted into a SpectraMax 190 micro plate reader (Molecular Devices). The reaction was monitored for $30-240 \mathrm{~min}$ at $405 \mathrm{~nm}$ as the remaining alkaline phosphatase hydrolyzed the pNPP introduced. The amount of pNPP hydrolysis was proportional to the amount of bound alkaline phosphatase. This reflects the number of neurons present in each well. The optical density was detected for each well and compared between groups.

Statistical analysis. To maximize statistical power and reduce familywise error, systematic comparisons were made using independent $t$ tests between control conditions. If no significant differences were detected, 

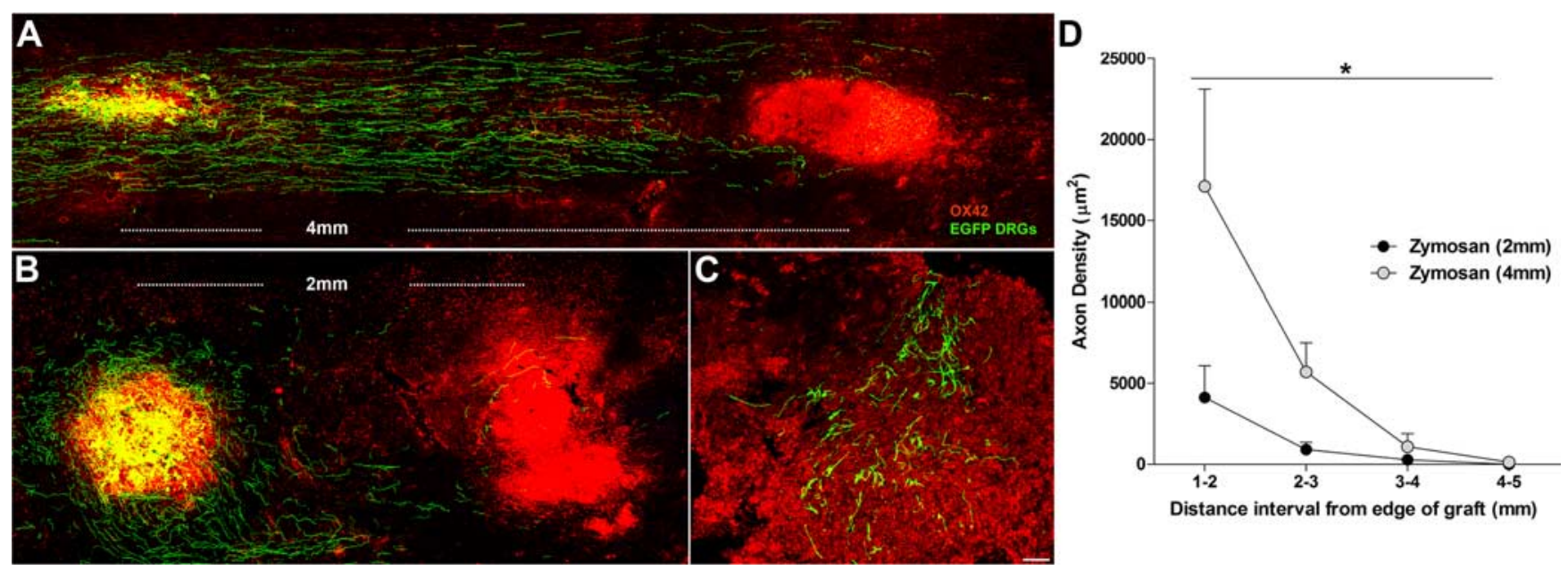

Figure 7. Macrophage activation close to neuron cell bodies impairs axon growth. $\boldsymbol{A}, \boldsymbol{B}$, Representative images of average axon growth after injecting zymosan $4 \mathrm{~mm}(\boldsymbol{A})$ or $2 \mathrm{~mm}(\boldsymbol{B})$ caudal to the DRG transplant (green, EGFP DRGs; red, 0X42). In the $2 \mathrm{~mm}$ group, axon growth is impaired ( $\boldsymbol{B}, \boldsymbol{D})$, and inflammation is enhanced in and around the graft compared with the $4 \mathrm{~mm}$ group ( $\boldsymbol{A}$.) C, In $\sim 29 \%$ (5 of 17) of cases, DRG grafts were not viable at $8 \mathrm{~d}$ if macrophages were activated within $2 \mathrm{~mm}$ of the graft. In contrast, when macrophages were activated $4 \mathrm{~mm}$ from transplants, all transplants were viable at $8 \mathrm{~d}$ and extended processes over several millimeters. D, When DRGs survived in the $2 \mathrm{~mm}$ group, the overall density of axonal outgrowth was significantly reduced $\left({ }^{*} p<\right.$ 0.05 , compared with the $4 \mathrm{~mm}$ group) as was the average length of the longest axon ( $2 \mathrm{~mm}$ zymosan, $2.9 \pm 0.4 \mathrm{~mm}$ vs $4 \mathrm{~mm}$ zymosan, $4.8 \pm 0.4 \mathrm{~mm} ; p<0.05)$. Note that $A$ is also pictured in Figure 2, but without $0 X 42$ labeling. Scale bar: $A, B, 146 \mu \mathrm{m} ; \boldsymbol{C}, 100 \mu \mathrm{m}$.

conditions were collapsed to increase statistical power. Grubb's test (extreme Studentized deviate method; http://www.graphpad.com/ quickcalcs/Grubbs1.cfm) was used to remove statistical outliers. Data were analyzed using ANOVA followed by Dunnett's or Tukey's test for multiple comparisons. Independent-samples $t$ tests were also used to compare two groups separately. Pearson's correlation coefficient was used to determine the statistical significance of regression data. All $p$ values $<0.05$ were considered significant. Unless noted otherwise, all data represent the mean \pm SEM. All analyses were performed using Prism 5.0 (GraphPad Software). Figures were prepared using Adobe Photoshop CS (Adobe Systems) and Prism 5.0.

\section{Results}

\section{ZAMs create a growth permissive environment and support} axon regeneration in vivo

To evaluate the ability of activated macrophages to promote axon regeneration in the spinal cord, we modified the protocol described by Davies et al. (1997, 1999). After micro-transplanting adult DRG neurons into the dorsal columns of the intact cervical spinal cord, growing axons were easily distinguished from host axons (Fig. 1). DRG axons grew rostral and caudal to the transplant site at rate of $\sim 0.7 \mathrm{~mm} / \mathrm{d}$ (Fig. 1).

Using this model, we asked whether focal intraspinal macrophage activation could enhance the growth of transplanted DRG axons in the spinal cord. Supplementing the injured spinal cord with activated macrophages caudal to the site of injury has been shown to promote axon regeneration in animals and was used in clinical trials to treat acute spinal cord injury (SCI) (Rapalino et al., 1998; Knoller et al., 2005). In an effort to maximally lure the growth cones of DRG axons into a microenvironment conditioned by activated macrophages, zymosan was injected $4 \mathrm{~mm}$ caudal to the site of DRG transplantation. DRGs and zymosan were injected at the same time to ensure that growing axons would approach the macrophage foci at the time of maximal macrophage activation ( $\sim 3 \mathrm{~d}$ after injection) (Popovich et al., 2002; Schonberg et al., 2007).

When compared with vehicle injection (saline) or micropipette alone, ZAMs increased the density of axons exiting the graft and the maximal distance that they grew (Fig. 2) [average length of longest axon (in mm), $3.2 \pm 0.5$ (control) vs $4.8 \pm 0.4$ (zymosan); $p<0.05$ ]. This may be a result of ZAMs creating a growthpermissive environment surrounding the inflammatory focus. Indeed, a "tunnel" of reactive microglia projected from the ZAM foci and colocalized with regions of demyelination (Fig. 3). A gradient of activated astrocytes also radiated from the ZAM foci as evidenced by increasing CNTF expression (Fig. 4).

DRG axons grew in straight trajectories through these tunnels and became tortuous or dystrophic as they reached the ZAM foci, often turning away from these cells (Figs. 3, 5). The abortive axon growth in and around areas containing ZAMs was associated with enhanced CSPG expression (Fig. 5) and enhanced phagocytic uptake of degenerating axon terminals (Fig. 6; supplemental Fig. 1, available at www.jneurosci.org as supplemental material). Phagocytic GFP + inclusions were observed in ZAMs in all (100\%) samples in which axons could be found approaching the interface. Importantly, no GFP + inclusions were found in activated microglia/macrophages surrounding the site of DRG injection (data not shown).

Zymosan injections created a dense, focal site of macrophage activation that was contained in the ascending dorsal columns. Because ZAMs can cause axotomy (Popovich et al., 2002), a field of Wallerian degeneration could be created in the dorsal columns between the zymosan and DRG injection sites. Consequently, the onset of CNTF upregulation or other pro-regenerative cues emanating from intratract glia could enhance regeneration. However, by reversing the position of the DRG transplant and the zymosan injection so that transplanted DRG neurons were positioned caudal rather than rostral to the zymosan injection site, Wallerian degeneration would proceed mostly rostral to the zymosan injection site. Thus, any changes in DRG axon growth between the zymosan or control injection sites could be attributed to activated macrophages. When we reversed the zymosan and DRG injection sites, we found a similar enhancement of axon growth from the DRG transplant site toward the foci of activated macrophages (supplemental Fig. 2, available at www.jneurosci. org as supplemental material). 


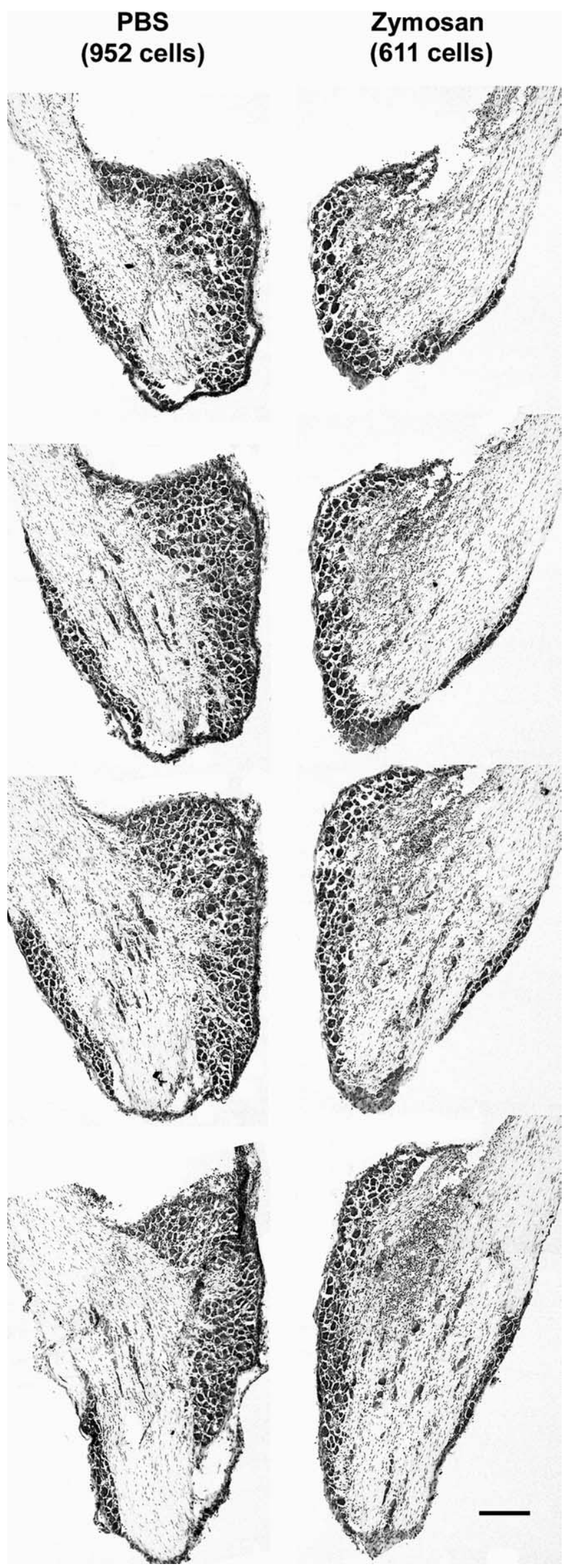

\section{Macrophages activated closer to DRGs fail to promote axon regeneration}

It has been shown that macrophages promote robust axon regeneration when they are activated near the soma of injured neurons (Lu and Richardson, 1991; Leon et al., 2000; Yin et al., 2003; Steinmetz et al., 2005). Thus, we predicted that injecting zymosan closer to the DRG transplant would increase axon regeneration in response to ZAMs. Contrary to our hypothesis, we found that axon growth was markedly impaired and inflammation was enhanced in and around the graft (Fig. 7, $A$ vs $B$ ). In fact, $\sim 29 \%$ (5 of 17) of DRG transplants failed to extend axons into the spinal parenchyma. In many cases, the grafts were not viable. For example, Figure $7 C$ is a representative DRG transplant that did not extend axons and appears to be dying. In comparison, when zymosan was injected distal ( $4 \mathrm{~mm}$ caudal) to the transplant, grafts were always viable, and DRG neurons extended axons a minimum of $4 \mathrm{~mm}$ into the spinal parenchyma.

ZAMs simultaneously promote axon growth and cell death The apparent killing of transplanted DRG neurons when macrophages were activated closer to the transplant site made us question the net effect of activated macrophages. That is, although macrophages can enhance axon regeneration, does the regenerative response compensate for or overshadow the ability of activated macrophages to kill neurons and glia? Also, do all macrophages promote regeneration and toxicity regardless of how they are activated?

\section{ZAMs kill neurons in the DRG}

Steinmetz et al. (2005) showed that intraganglionic injection of zymosan activates macrophages and promotes functionally significant regeneration of injured DRG axons; however, ZAM toxicity was never evaluated in their preparation. In that model, ZAMs colocalize with the soma of DRG neurons. Based on data in Figure 7, we predicted that intraganglionic ZAMs would kill at least a portion of DRG neurons. Using a modification of the Steinmetz model, we injected into intact L4/L5 DRGs $10 \%$ of the volume and concentration of zymosan $(1.25 \mu \mathrm{g}$ in $100 \mathrm{nl})$ that was shown by Steinmetz et al. (2005) to promote axon regeneration. This dose/volume approximated what was injected into the spinal cord in Figures 2-7. Despite the markedly reduced concentration of zymosan in our preparation, robust inflammation and neurotoxicity were evident in the DRG within $72 \mathrm{~h}$. For example, when we cut and quantified neurons throughout the depth of an injection site, we found that $~ 33 \%$ of DRG neurons were killed (Fig. 8). PBS injections into the contralateral ganglia failed to elicit inflammation or promote neuronal killing (Fig. 8).

\section{ZAMs are neurotoxic in the spinal cord}

We have previously shown that clodronate liposomes selectively kill circulating monocytes and reduce the accumulation of intraspinal macrophages after traumatic SCI (Popovich et al., 1999; Popovich et al., 2003). This technique removes most circulating monocytes and is a proven way to minimize the recruitment of blood monocytes to sites of inflammation (van Rooijen and Vannieuwmegen, 1984). To determine whether the neurotoxic effects of intraspinal zymosan are caused by monocyte-derived macro-

\section{$\leftarrow$}

Figure 8. ZAMs are neurotoxic in DRGs. Serial sections cut through cresyl violet-stained DRGs injected with PBS (control) or zymosan (3 d after injection) reveal marked cell loss and gliosis in zymosan-injected ganglia. In this specimen, DRG neurons were decreased $\sim 33 \%$ by zymosan versus neurons in PBS-injected DRGs. Scale bar, $200 \mu \mathrm{m}$. 


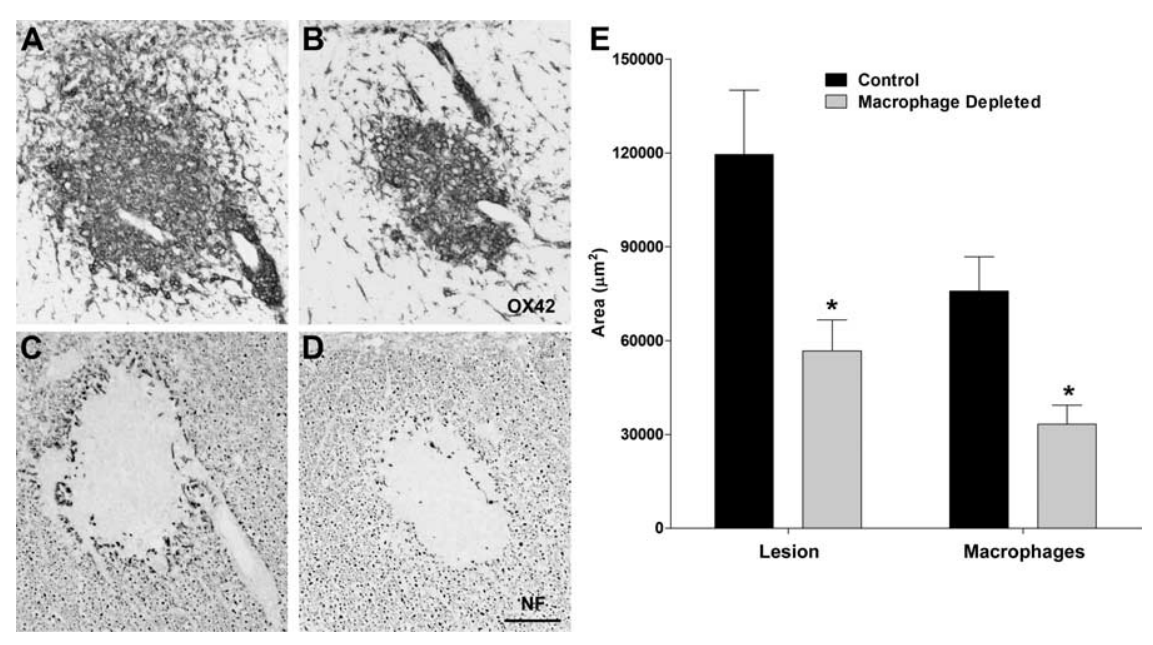

Figure 9. Intraspinal zymosan causes pathology in part via recruitment of blood monocytes. $\boldsymbol{A}$, Zymosan microinjection potently activates CNS macrophages (OX42+ cells) at the site of injection within $7 \mathrm{~d}$. $\boldsymbol{B}$, The zymosan-mediated macrophage response is significantly reduced in macrophage-depleted subjects. $\boldsymbol{C}, \boldsymbol{D}$, Adjacent sections stained with neurofilament (NF) antibody show that ZAMs cause axonal pathology $(\boldsymbol{C})$, which is significantly reduced after macrophage depletion $(\boldsymbol{D})$. Images are from subjects representing the statistical mean for the control $(\boldsymbol{A}, \boldsymbol{C})$ and macrophage-depleted $(\boldsymbol{B}, \boldsymbol{D})$ groups. $\boldsymbol{E}$, Quantitative analysis of images in $\boldsymbol{A}-\boldsymbol{D}$ confirm that macrophage depletion reduces intraspinal accumulation of macrophages $\sim 50 \%$ with a concomitant decrease in axon pathology ( ${ }^{*} p<0.05$, vs controls). Scale bar: $\boldsymbol{A}-\boldsymbol{D}, 100 \mu \mathrm{m}$.

phages (as opposed to resident microglia), clodronate liposomes or PBS (control) were injected intravenously on days 1,3 , and 6 after intraspinal zymosan injection. Clodronate liposomes significantly reduced macrophage-mediated damage at the site of injection. Specifically, the area of activated macrophages was reduced by $>50 \%$ and was accompanied by a significant reduction in lesion area (Fig. 9). These data suggest that monocyte-derived macrophages cause a substantial portion of zymosan-induced pathology.

\section{Macrophage-mediated axon regeneration and neurotoxicity in vitro}

As shown above, intraspinal macrophage activation has dramatic effects on glia and axons in the milieu immediately surrounding the site of macrophage activation. Depending on where macrophages are activated relative to the soma of the regenerating axons, growth or toxicity was observed. To refine these analyses further, we tested the direct effects of ZAMs on neurons by stimulating adult DRG neurons in vitro with medium conditioned by unstimulated or zymosan-stimulated macrophages. Macrophages were derived from primary bone-marrow cells as described previously (Longbrake et al., 2007). Importantly, these cells mimic the functional potential of macrophages that infiltrate the injured spinal cord (Longbrake et al., 2007).

When DRG neurons were exposed for $24 \mathrm{~h}$ to ZAMconditioned medium (zymosan MCM), the overall complexity and length of DRG axons was increased compared with medium or unstimulated MCM, verifying the growth-promoting effect of ZAMs (Fig. 10). These dramatic effects (as illustrated in Fig. 10 A) were easily quantified using a modified Sholl analysis (Fig. 10 B) (Sholl, 1953). However, in these same cultures, the total neuron number was decreased relative to control wells (Fig. 10C). When plotted as function of axon branching and overall axon length (i.e., regenerative index), the number of surviving DRG neurons decreased as indices of regeneration increased. These data suggest that macrophages simultaneously release a mixture of proregenerative and neurotoxic factors and that a subset of neurons is resistant to the neurotoxic effects of inflammation, at least after $24 \mathrm{~h}$ of incubation.

Because the net effect of these toxins and growth factors should be revealed with longer exposure times, we extended the length of time that neurons were exposed to MCM. Prolonged exposure is relevant to in vivo pathology since macrophages persist at sites of CNS inflammation for many weeks. After $48 \mathrm{~h}$ in vitro, the growth-promoting effects of zymosan MCM were lost. Instead of seeing neurons with long and elaborate axons like those found at $24 \mathrm{~h}$, a large proportion of DRG neurons were degenerating or had already died (Fig. 11A,B). The amount of cell death exceeded that observed after $24 \mathrm{~h}$ of stimulation with zymosan MCM (Fig. $11 B)$. Of those neurons that appeared healthy, the overall length and complexity of their axons was decreased relative to controls (Fig. 11C).

Yin et al. (2003) showed that reducing the concentration of zymosan injected into the eye increased the survival of RGCs while maintaining improved axon regeneration through the injured optic nerve (Yin et al., 2003). In an attempt to uncouple the neurotoxic and pro-regenerative effects of ZAMs, we applied serial dilutions of zymosan MCM to DRGs as above. We found that the regenerative and toxic effects could be partially titrated but never uncoupled (supplemental Fig. 3, available at www.jneurosci.org as supplemental material). For example, a 1:2 dilution of zymosan MCM promoted slightly more DRG axon growth than "neat" zymosan MCM at $24 \mathrm{~h}$ (supplemental Fig. $4 A$, available at www.jneurosci.org as supplemental material); however, by $48 \mathrm{~h}$ the diluted media samples were equally neurotoxic and were unable to enhance DRG axon growth (supplemental Fig. $3 A, B$, available at www.jneurosci.org as supplemental material).

To test whether neuronal killing by ZAMs was specific for sensory neurons, the above assays were repeated using cultures of cortical neurons. Mouse cortical neurons were mostly resistant to killing by unstimulated MCM (Fig. 12); however, toxicity was markedly enhanced by zymosan MCM.

\section{The growth-promoting and neurotoxic potential of macrophages is ligand dependent}

Zymosan activates spinal cord microglia and blood monocytes predominantly by Toll-like receptor-2 (TLR2) (Carlo and Fiore, 1958; Gantner et al., 2003; Underhill, 2003). Via this receptor, intracellular signaling cascades could trigger pro-regenerative and neurotoxic functions in CNS macrophages. To determine whether other modes of macrophage activation can simultaneously elicit axon growth and cell killing, we repeated the in vivo and in vitro assays described above after stimulating macrophages with the classical pro-inflammatory stimulus and TLR4 agonist, LPS.

Using our in vitro assay of neuron death, LPS MCM was found to be only mildly neurotoxic (not significantly different from control MCM or medium) to DRG neurons after 24 or $48 \mathrm{~h}$ of exposure (Fig. $11 \mathrm{~B}$ ). Furthermore, LPS MCM had no effect on DRG axon length $[254 \pm 27$ (unstimulated) vs $337 \pm 34 \mu \mathrm{m}$ 
A
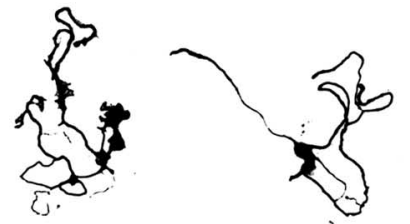

Media

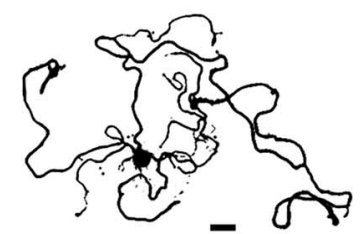

Zymosan MCM
B
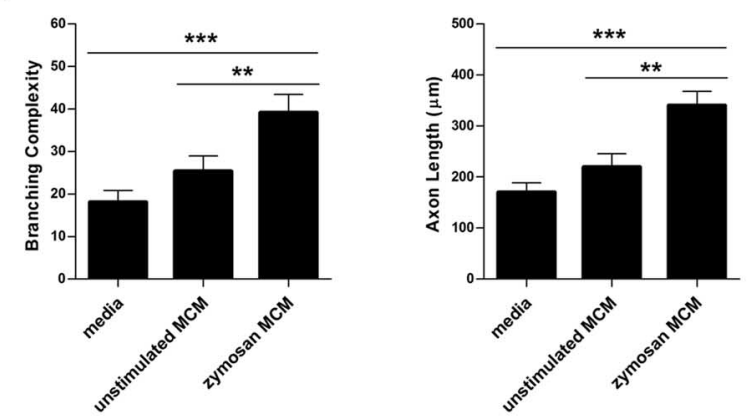

C

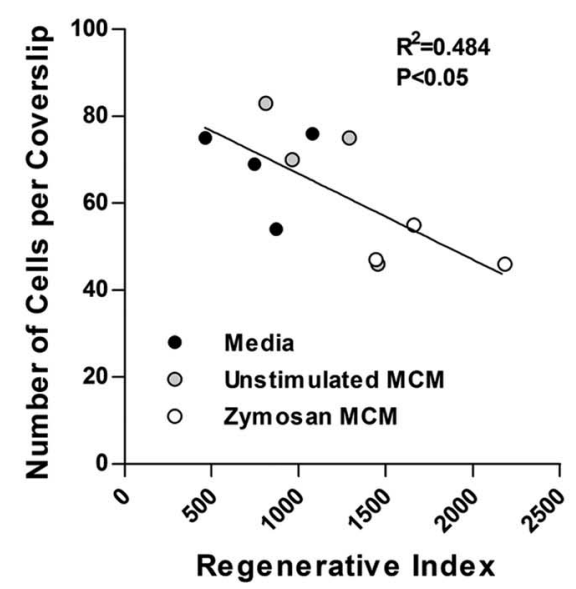

Figure 10. ZAMs simultaneously promote axon growth and killing of DRG neurons in vitro. $\boldsymbol{A}$, $\beta$-Tubulin III-stained cellular profiles representative of the average branching complexity and axon length of neurons from cultures treated for $24 \mathrm{~h}$ with media, unstimulated MCM, or zymosan-stimulated MCM. Scale bar, $40 \mu \mathrm{m}$. $\boldsymbol{B}$, A semiautomated quantification scheme, based on the technique of Sholl (1953) (see also Materials and Methods), was used to quantify the effects of different MCMs on axonal sprouting and axon length. In each case, zymosan MCM significantly increased these indices of growth/regeneration ( ${ }^{* * *} p<0.001$, zymosan vs media; ${ }^{* *} p<0.01$, zymosan vs unstimulated MCM). C, An inverse relationship exists between the overall axon regenerative index (composite of axon branching and length) and neuron survival. Note that zymosan MCM stimulates extensive axon growth while promoting neuronal killing. Cell killing was inferred based on fewer cells per coverslip despite plating equal numbers of DRGs in each well.

(LPS); $p=0.059]$ or branching complexity [28.4 \pm 3.5 (unstimulated) vs $32.5 \pm 3.4$ (LPS); $p=0.409]$ after $24 \mathrm{~h}$, but the complexity of axonal branching was reduced in DRG neurons after $48 \mathrm{~h}$ (Fig. 11C). In contrast to DRGs, LPS MCM (24 h) was toxic to cortical neurons (Fig. 12C).

As we have reported previously, intraspinal injections of LPS activates macrophages but does not cause marked pathology to neurons or myelin (Fig. 13 A,B) (Schonberg et al., 2007). Despite the absence of overt pathology at/near the LPS injection site (Fig. $13 A, B)$, TLR4-mediated macrophage activation did not enhance growth of transplanted DRG axons. This was true whether LPS was injected distal $(4 \mathrm{~mm})$ or proximal $(2 \mathrm{~mm})$ to the transplant (Fig. 13C). Thus, LPS-activated macrophages are less neurotoxic than ZAMs but they also lacked the ability to stimulate axon growth, suggesting again that the pro-regenerative and neurotoxic effects of activated macrophages are coupled.

\section{Discussion}

CNS trauma elicits a macrophage response composed of resident microglia and blood monocytes. Collectively, these cells are believed to be essential for promoting CNS remyelination and regeneration of injured CNS axons (Rapalino et al., 1998; Kotter et al., 2001; Benowitz and Yin, 2007). Attempts to augment this repair capacity in humans culminated in a phase I autologous macrophage transplantation (ProCord) trial for treating acute SCI (Knoller et al., 2005). It was predicted that injecting activated macrophages into the caudal pole of SCI lesions would improve removal of inhibitory molecules and create a gradient of tropic or trophic factors leading to enhanced axon growth across/around sites of injury (Schwartz et al., 1999). Although phase II trials were suspended for unspecified reasons, the advent of this trial underscores the hope for manipulating macrophages to promote CNS repair. Unfortunately, macrophages also kill neurons and glia as a normal part of their conserved response to tissue damage (for review see, Popovich and Longbrake, 2008).

In the CNS, the idea that macrophages can exert divergent functions is appreciated but rarely documented, especially in vivo. Indeed, the range of ligand/receptor interactions involved in shaping CNS macrophage function in a given context is primarily unknown. Also, it is difficult to separate the injury/repair effects of activated macrophages from those initiated by other cells directly affected by trauma. Here, we used controlled in vivo and in vitro models to unequivocally show that activated macrophages simultaneously promote axon regeneration and neurotoxicity. Regenerating DRG axons course through a permissive glial substrate induced by activated macrophages. These axons then abruptly turn or "die back" as they encounter macrophage foci composed of mostly recruited blood monocytes, the latter of which cause pathology and were associated with a growth inhibitory CSPG "cloud." This mimics what happens when axons encounter macrophage-enriched lesions created by acute trauma (Davies et al., 1999; Horn et al., 2008) and may have caused us to underestimate the magnitude of axon growth stimulated by ZAMs in our model. An examination of axon growth at earlier times after DRG/zymosan injection would be needed to test this hypothesis.

When macrophages were activated close to DRG soma, macrophage-mediated killing predominated. The toxic effects of intraganglionic zymosan injection were intriguing (Fig. 8) since coupling zymosan injections with CSPG degradation has been shown to promote regeneration of injured DRG axons in vivo (Steinmetz et al., 2005). Furthermore, using zymosan and LPS as prototypical stimuli that elicit a range of macrophage functions relevant to CNS injury/repair, we show that not all activated macrophages are equally adept at causing tissue repair or cell killing. Given that traumatic CNS injuries elicit a similarly heterogeneous macrophage response, these data illustrate the complexities and challenges of controlling and manipulating macrophages with the goal of repairing the CNS.

\section{Macrophage-mediated regeneration is coupled with neuropathology}

Clearly, simply removing or augmenting the effects of these cells at sites of injury cannot easily predict macrophage-mediated ef- 
A

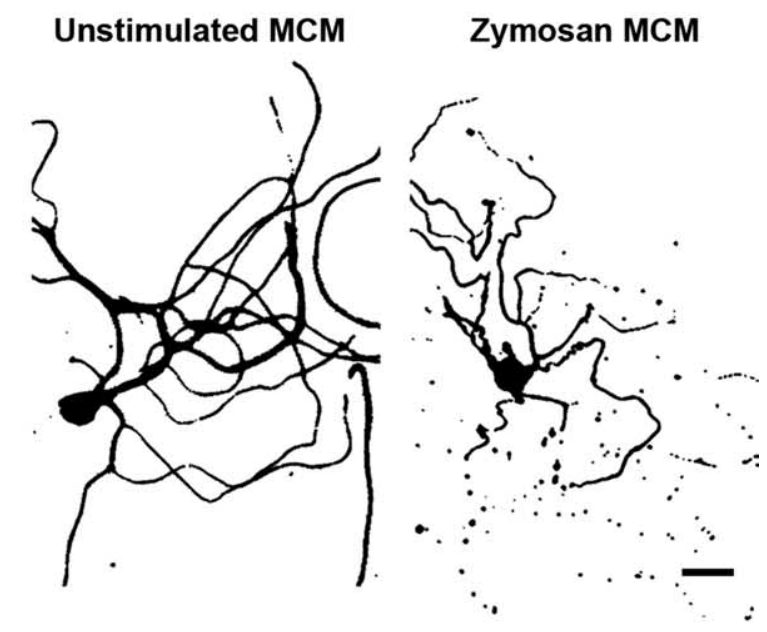

B

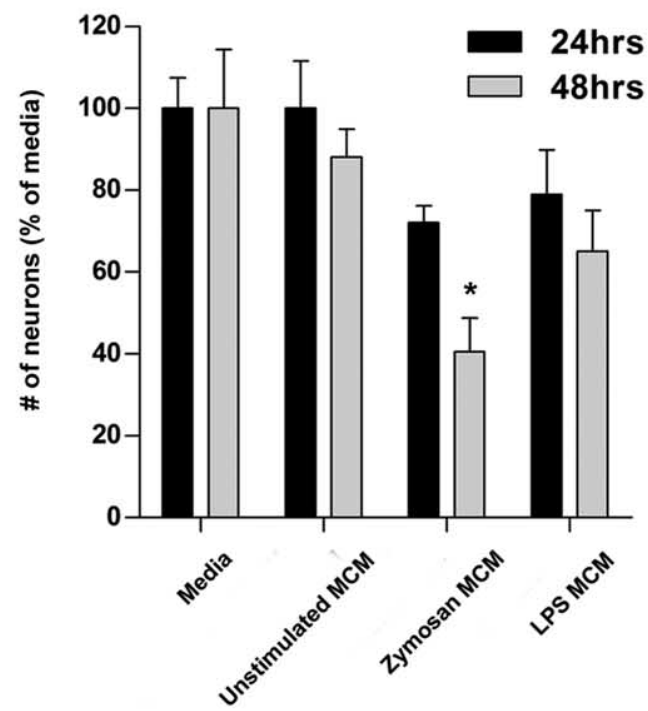

C
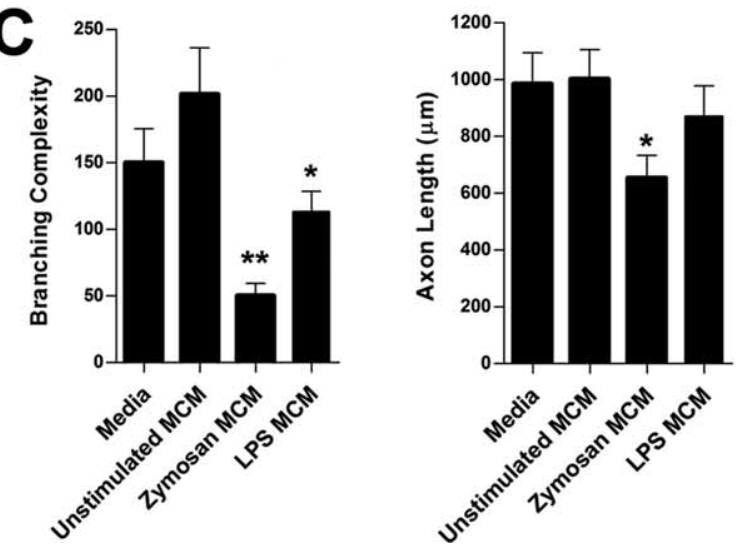

Figure 11. Prolonged exposure of neurons to zymosan MCM results in toxicity and axonal degeneration. $\boldsymbol{A}$, Examples of $\beta$-tubulin III + DRG neurons exposed for $48 \mathrm{~h}$ to unstimulated or zymosan MCM. After $48 \mathrm{~h}$, neurons exposed to zymosan MCM become dystrophic and begin to degenerate. Scale bar, $180 \mu \mathrm{m}$. B, A comparison of DRG neuron survival at 24 and $48 \mathrm{~h}$ after stimulation with control media or different types of MCM. Only zymosan MCM kills neurons after $48 \mathrm{~h}$ of stimulation ( ${ }^{*} p<0.05$, vs $24 \mathrm{~h}$ zymosan MCM). C, Quantification of neurons with intact axons in each group show that prolonged stimulation with zymosan MCM reduces the overall complexity and length of DRG axons ( ${ }^{* *} p<0.01$, compared with control media; ${ }^{*} p<0.05$, compared with unstimulated MCM). Interestingly, 48 h MCM from LPS-stimulated macrophages also reduces axonal branching ( $p<0.05$, vs unstimulated MCM) but not length. fects on axon growth and cell death. Systemic depletion of circulating monocytes reduces pathology and improves regenerative sprouting at sites of contusive SCI (Popovich et al., 1999) but has no effect on the ability of intraocular inflammation to promote regeneration of injured RGCs (Hauk et al., 2008). In the present study, macrophage depletion reduces pathology caused by focal intraspinal injection of zymosan, but it is difficult to predict whether this would affect DRG axon growth since the positive and negative aspects of the activated macrophages would be lost. Gain-of-function studies targeting CNS macrophages may be equally ambiguous. For example, in a SCI model, LPS-activated macrophages enhanced phagocytic removal of myelin growth inhibitory proteins, but without causing toxicity or regeneration (Vallieres et al., 2006). Collectively, these data underscore the importance of understanding how the lesion microenvironment influences epigenetic regulation of macrophage function and how those functions influence cell survival or repair.

In vivo, we found that ZAMs promote axon growth when they are activated distal to axon growth cones. Macrophages have been shown to modify the astrogliotic scar and enhance the growthpermissiveness of injured CNS tissue, in part through increased astrocyte production of brain-derived neurotrophic factor (BDNF) and CNTF (David et al., 1990; Savli et al., 2004; Muller et al., 2007; Wu et al., 2007). In our model, astrocytes create a CNTF gradient emanating from the edge of zymosan injection (Fig. 4). Notably, CNTF was not increased in the ZAM foci, which may explain why DRG axons grew toward but not through ZAMs. However, other cells and trophic factors undoubtedly synergize to promote axon growth. As proteins of different molecular weight diffuse from the ZAM foci, they could create microenvironments with distinct effects on axon growth/neuron survival. Indeed, Yin et al. (2003) showed that ZAM-derived neurotoxins and neurotrophic factors can be separated based on molecular weight with neurotoxins being larger than macrophage-derived neurotrophic factors. If we consider the spinal cord as an in vivo filtration "gel," we would expect neurotoxic factors to migrate slowly and remain nearby ZAM foci while neurotrophic factors would diffuse more freely. This may explain why ZAMs activated close to the DRG transplant site caused neuron atrophy and axon collapse. It also suggests that the effects we observed in vitro, using $\mathrm{MCM}$, reflect an initial growth-promoting effect of neurotrophins that are subsequently overridden by neurotoxic molecules. Future studies are needed to establish how different stimuli in the lesion microenvironment control macrophage function and then relate these changes to neuron survival and axon growth.

Modeling the consequences of macrophage activation in CNS The opposing functions of CNS macrophages on neurons and glia in vivo are undoubtedly triggered by an array of receptor/ ligand interactions. Of these, TLRs play a fundamental role in regulating the balance between macrophage-mediated injury/repair (Nguyen et al., 2002; Kigerl et al., 2007). In the CNS, TLRs are found mostly on microglia and macrophages (Laflamme and Rivest, 2001; Zekki et al., 2002), although astrocytes, oligodendrocytes, stem cells, and neurons also express TLRs (Bsibsi et al., 2002; Ma et al., 2006; Cameron et al., 2007; Rolls et al., 2007). At sites of injury, TLRs bind endogenous non-pathogenic molecules known as danger-associated molecular patterns (DAMPs). These naturally occurring TLR ligands may serve a physiological role in alerting macrophages to changes in tissue homeostasis (Zhang and Schluesener, 2006; Bianchi, 2007). Many DAMPs, including heat shock proteins, necrotic cell debris, degradation products of the extracellular matrix (e.g., fibronectin, hyaluronic acid), high- 
mobility group box 1 , and mRNA exist at sites of CNS injury and could help shape the divergent functions of CNS macrophages (Basu et al., 2000; Li et al., 2001; Okamura et al., 2001; Termeer et al., 2002; $\mathrm{Yu}$ et al., 2006). However, it is not yet known which DAMPs predominate in a given pathological condition or whether these molecules can be used as reliable model stimuli for triggering macrophage responses of relevance to CNS injury. For example, it is known that degenerating DRG neurons release nonproteinaceous byproducts that induce a TLR 2 and possibly TLR4-dependent pro-inflammatory phenotype in microglia (Tanga et al., 2005; Kim et al., 2007). Activated in this way, microglia can be toxic to neurons and glia (Lehnardt et al., 2006). In contrast, a variety of DAMPs trigger macrophages to release growth factors. For example, oncomodulin, glial cell line-derived neurotrophic factor (GDNF), BDNF, and NGF are released from activated macrophages and increase axonal outgrowth from different types of neurons (Lentz et al., 1999; Batchelor et al., 2002; Yin et al., 2006; Nakajima et al., 2007).

Zymosan and LPS, pathogenic TLR2, and TLR4 ligands, respectively, activate microglia/macrophages in vivo and produce a spectrum of the injurious and reparative responses found in models of traumatic CNS injury (Fitch et al., 1999; Popovich et al., 2002; McPhail et al., 2004; Hossain-Ibrahim et al., 2006; Vallieres et al., 2006; Schonberg et al., 2007). Here, we used these ligands to induce a robust and predictable inflammatory response at the leading edge of growing axons and noted both positive and negative effects. Although these stimuli may represent extremes in the activation sequence triggered by CNS injury, they cannot be dismissed as irrelevant since they trigger highly conserved intracellular signaling pathways that elicit macrophage functions relevant in CNS injury. Intraspinal injection of zymosan elicits monocyte recruitment and creates a gradient of activated microglia and astrocytes that radiate from the injection site (Fig. 3). This resembles the cellular response elicited by contusive SCI or axonal transection in the brain (Popovich et al., 1997; Batchelor et al., 1999). Just like zymosan, axon transection in brain activates microglia in a TLR2-dependent manner (Babcock et al., 2006) creating a gradient of GDNF and BDNF that supports regenerative sprouting (Batchelor et al., 1999), reminiscent of data shown in Figure 4. Axons grow through these gradients but not into or through inflammatory foci enriched with monocytederived macrophages. Again, this mimics how axons respond as they negotiate macrophage-enriched necrotic foci in hemorrhagic lesions caused by brain trauma or SCI. A remaining challenge is to define the endogenous factors that trigger proregenerative and neurotoxic functions in macrophages and learn how to manipulate the resultant signaling pathways to maximize CNS repair.

\section{References}

Babcock AA, Wirenfeldt M, Holm T, Nielsen HH, Dissing-Olesen L, ToftHansen H, Millward JM, Landmann R, Rivest S, Finsen B, Owens T (2006) Toll-like receptor 2 signaling in response to brain injury: an innate bridge to neuroinflammation. J Neurosci 26:12826-12837.
Basu S, Binder RJ, Suto R, Anderson KM, Srivastava PK (2000) Necrotic but not apoptotic cell death releases heat shock proteins, which deliver a partial maturation signal to dendritic cells and activate the NF-kappa B pathway. Int Immunol 12:1539-1546.

Batchelor PE, Liberatore GT, Wong JYF, Porritt MJ, Frerichs F, Donnan GA, Howells DW (1999) Activated macrophages and microglia induce dopaminergic sprouting in the injured striatum sand express brain-derived neurotrophic factor and glial cell line-derived neurotrophic factor. J Neurosci 19:1708-1716.

Batchelor PE, Porritt MJ, Martinello P, Parish CL, Liberatore GT, Donnan GA, Howells DW (2002) Macrophages and microglia produce local trophic gradients that stimulate axonal sprouting toward but not beyond the wound edge. Mol Cell Neurosci 21:436-453.

Benowitz LI, Yin YQ (2007) Combinatorial treatments for promoting axon regeneration in the CNS: strategies for overcoming inhibitory signals and activating neurons' intrinsic growth state. Dev Neurobiol 67:1148-1165.

Bianchi ME (2007) DAMPs, PAMPs and alarmins: all we need to know about danger. J Leukoc Biol 81:1-5.

Brooke SM, Bliss TM, Franklin LR, Sapolsky RM (1999) Quantification of neuron survival in monolayer cultures using an enzyme-linked immunosorbent assay approach, rather than by cell counting. Neurosci Lett 267:21-24.

Bruckner G, Bringmann A, Hartig W, Koppe G, Delpech B, Brauer K (1998) Acute and long-lasting changes in extracellular-matrix chondroitinsulphate proteoglycans induced by injection of chondroitinase $\mathrm{ABC}$ in the adult rat brain. Exp Brain Res 121:300-310.

Bsibsi M, Ravid R, Gveric D, van Noort JM (2002) Broad expression of Toll-like receptors in the human central nervous system. J Neuropathol Exp Neurol 61:1013-1021.

Cameron JS, Alexopoulou L, Sloane JA, DiBernardo AB, Ma Y, Kosaras B, Flavell R, Strittmatter SM, Volpe J, Sidman R, Vartanian T (2007) Tolllike receptor 3 is a potent negative regulator of axonal growth in mammals. J Neurosci 27:13033-13041.

Carlo FJD, Fiore JV (1958) On the composition of zymosan. Science 127:756-757.

David S, Bouchard C, Tsatas O, Giftochristos N (1990) Macrophages can modify the nonpermissive nature of the adult mammalian central nervous system. Neuron 5:463-469.

Davies SJA, Fitch MT, Memberg SP, Hall AK, Raisman G, Silver J (1997) 

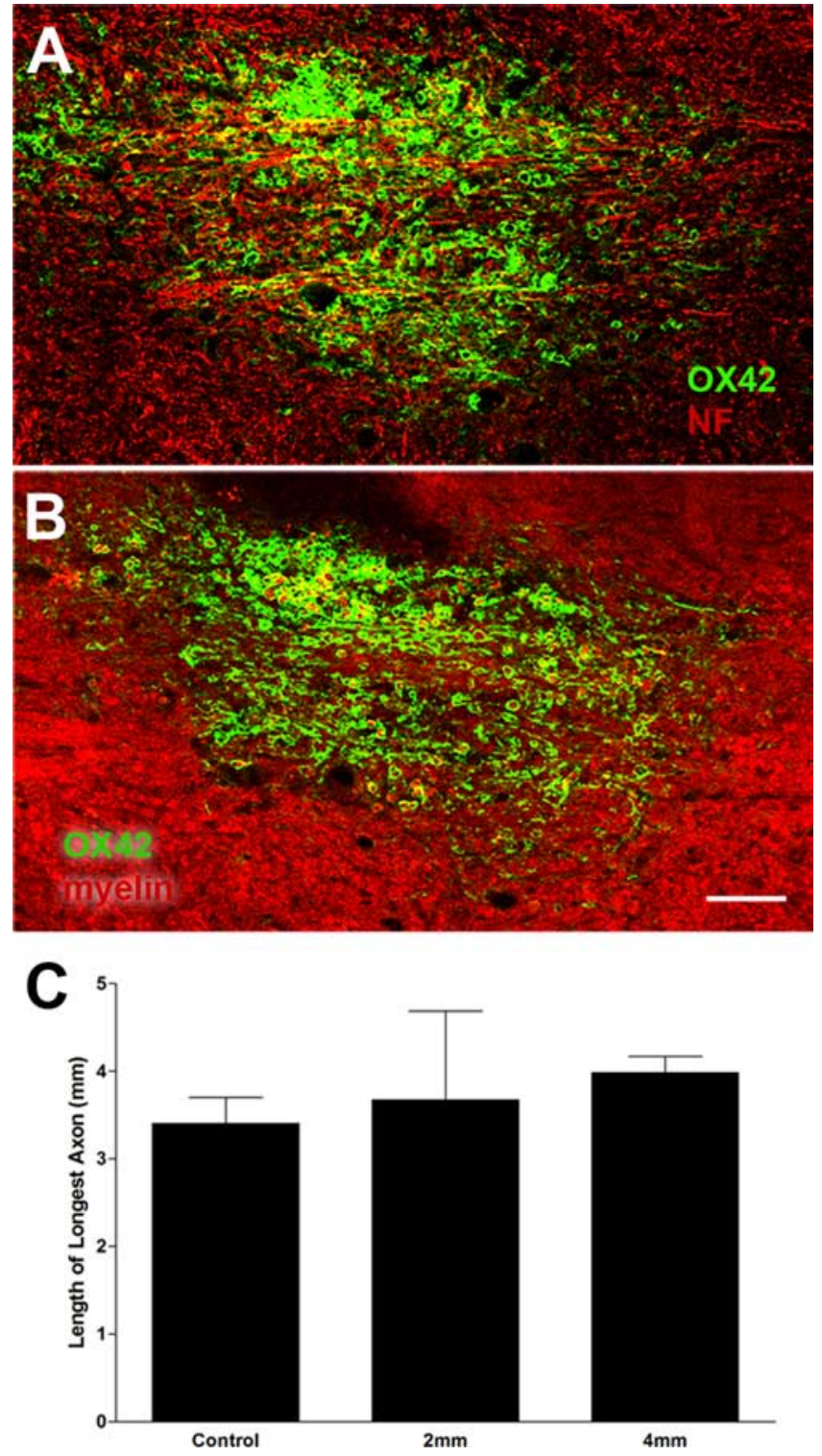

Figure 13. The ability of macrophages to promote axon growth is specific to the activating ligand. $A, B$, Cervical spinal cord sections stained $8 \mathrm{~d}$ after intraspinal LPS injection. In contrast to the effects ofZAMs (see Figs. 3-6), intraspinal LPS activates macrophages (0X42; green) without causing profound axon [neurofilament (NF); red; $\boldsymbol{A}$ )] or myelin (fluoromyelin; $\boldsymbol{B}$ ) pathology. $\boldsymbol{A}$, Intact axons can be seen coursing through the activated macrophages. $\boldsymbol{B}$, Some myelin pallor is evident, but this does not extend beyond the injection site. Scale bar, $100 \mu \mathrm{m}$. C, Unlike zymosan, LPS has no effect on the growth of transplanted DRG neurons. LPS was injected $2 \mathrm{~mm}$ ( $p=0.743)$ or $4 \mathrm{~mm}(p=0.317)$ caudal to the DRG transplant.

Regeneration of adult axons in white matter tracts of the central nervous system. Nature 390:680-683

Davies SJA, Goucher DR, Doller C, Silver J (1999) Robust regeneration of adult sensory axons in degenerating white matter of the adult rat spinal cord. J Neurosci 19:5810-5822.

Fitch MT, Doller C, Combs CK, Landreth GE, Silver J (1999) Cellular and molecular mechanisms of glial scarring and progressive cavitation: in vivo and in vitro analysis of inflammation-induced secondary injury after CNS trauma. J Neurosci 19:8182-8198.

Gantner BN, Simmons RM, Canavera SJ, Akira S, Underhill DM (2003) Collaborative induction of inflammatory responses by dectin- 1 and Tolllike receptor 2. J Exp Med 197:1107-1117.

Gray M, Palispis W, Popovich PG, van Rooijen N, Gupta R (2007) Macrophage depletion alters the blood-nerve barrier without affecting Schwann cell function after neural injury. J Neurosci Res 85:766-777.

Hauk TG, Muller A, Lee J, Schwendener R, Fischer D (2008) Neuroprotec- tive and axon growth promoting effects of intraocular inflammation do not depend on oncomodulin or the presence of large numbers of activated macrophages. Exp Neurol 209:469-482.

Horn KP, Busch SA, Hawthorne AL, van Rooijen N, Silver J (2008) Another barrier to regeneration in the CNS: activated macrophages induce extensive retraction of dystrophic axons through direct physical interactions. J Neurosci 28:9330-9341.

Hossain-Ibrahim MK, Rezajooi K, MacNally JK, Mason MRJ, Lieberman AR, Anderson PN (2006) Effects of lipopolysaccharide-induced inflammation on expression of growth-associated genes by corticospinal neurons. BMC Neurosci 7:8.

Kigerl KA, Lai WM, Rivest S, Hart RP, Satoskar AR, Popovich PG (2007) Toll-like receptor (TLR)-2 and TLR-4 regulate inflammation, gliosis, and myelin sparing after spinal cord injury. J Neurochem 102:37-50.

Kim D, Kim MA, Cho IH, Kim MS, Lee S, Jo EK, Choi SY, Park K, Kim JS Akira S, Na HS, Oh SB, Lee SJ (2007) A critical role of Toll-like receptor 2 in nerve injury-induced spinal cord glial cell activation and pain hypersensitivity. J Biol Chem 282:14975-14983.

Knoller N, Auerbach G, Fulga V, Zelig G, Attias J, Bakimer R, Marder JB Yoles E, Belkin M, Schwartz M, Hadani M (2005) Clinical experience using incubated autologous macrophages as a treatment for complete spinal cord injury: phase I study results. J Neurosurg 3:173-181.

Kotter MR, Setzu A, Sim FJ, van Rooijen N, Franklin RJM (2001) Macrophage depletion impairs oligodendrocyte remyelination following lysolecithin-induced demyelination. Glia 35:204-212.

Laflamme N, Rivest S (2001) Toll-like receptor 4: the missing link of the cerebral innate immune response triggered by circulating gram-negative bacterial cell wall components. FASEB J 15:155-163.

Lehnardt S, Henneke P, Lien E, Kasper DL, Volpe JJ, Bechmann I, Nitsch R, Weber JR, Golenbock DT, Vartanian T (2006) A mechanism for neurodegeneration induced by group $\mathrm{B}$ streptococci through activation of the TLR2/MyD88 pathway in microglia. J Immunol 177:583-592.

Lentz SI, Knudson CM, Korsmeyer SJ, Snider WD (1999) Neurotrophins support the development of diverse sensory axon morphologies. J Neurosci 19:1038-1048.

Leon S, Yin YQ, Nguyen J, Irwin N, Benowitz LI (2000) Lens injury stimulates axon regeneration in the mature rat optic nerve. J Neurosci 20:4615-4626.

Li M, Carpio DF, Zheng Y, Bruzzo P, Singh V, Ouaaz F, Medzhitov RM, Beg AA (2001) An essential role of the NF-kappa B/Toll-like receptor pathway in induction of inflammatory and tissue-repair gene expression by necrotic cells. J Immunol 166:7128-7135.

Lindsay R, Winter J, Evison C (1991) Culture of adult mammalian peripheral neurons. In: Cellular neurobiology: a practical approach (Chad J, Wheals H, eds), pp 3-17. New York: IRL.

Longbrake EE, Lai W, Ankeny DP, Popovich PG (2007) Characterization and modeling of monocyte-derived macrophages after spinal cord injury. J Neurochem 102:1083-1094.

Lu X, Richardson PM (1991) Inflammation near the nerve-cell body enhances axonal regeneration. J Neurosci 11:972-978.

Ma Y, Li J, Chiu I, Wang Y, Sloane JA, Lu J, Kosaras B, Sidman RL, Volpe JJ Vartanian T (2006) Toll-like receptor 8 functions as a negative regulator of neurite outgrowth and inducer of neuronal apoptosis. J Cell Biol 175:209-215

Mallat M, Chamak B (1994) Brain macrophages: neurotoxic or neurotrophic effector cells? J Leukoc Biol 56:416-422.

McPhail LT, Stirling DP, Tetzlaff W, Kwiecien JM, Ramer MS (2004) The contribution of activated phagocytes and myelin degeneration to axonal retraction/dieback following spinal cord injury. Eur J Neurosci 20:1984-1994.

Muller A, Hauk TG, Fischer D (2007) Astrocyte-derived CNTF switches mature RGCs to a regenerative state following inflammatory stimulation. Brain 130:3308-3320.

Nahrendorf M, Swirski FK, Aikawa E, Stangenberg L, Wurdinger T, Figueiredo JL, Libby P, Weissleder R, Pittet MJ (2007) The healing myocardium sequentially mobilizes two monocyte subsets with divergent and complementary functions. J Exp Med 204:3037-3047.

Nakajima K, Tohyama Y, Maeda S, Kohsaka S, Kurihara T (2007) Neuronal regulation by which microglia enhance the production of neurotrophic factors for GABAergic, catecholaminergic, and cholinergic neurons. Neurochem Int 50:807-820. 
Nguyen MD, Julien JP, Rivest S (2002) Innate immunity: the missing link in neuroprotection and neurodegeneration? Nat Rev Neurosci 3:216-227.

Okamura Y, Watari M, Jerud ES, Young DW, Ishizaka ST, Rose J, Chow JC, Strauss JF III (2001) The extra domain A of fibronectin activates Tolllike receptor 4. J Biol Chem 276:10229-10233.

Popovich PG, Longbrake EE (2008) Perspectives-Opinion: Can the immune system be harnessed to repair the CNS? Nat Rev Neurosci 9:481-493.

Popovich PG, Wei P, Stokes BT (1997) Cellular inflammatory response after spinal cord injury in Sprague-Dawley and Lewis rats. J Comp Neurol 377:443-464.

Popovich PG, Guan Z, Wei P, Huitinga I, van Rooijen N, Stokes BT (1999) Depletion of hematogenous macrophages promotes partial hindlimb recovery and neuroanatomical repair after experimental spinal cord injury. Exp Neurol 158:351-365.

Popovich PG, Guan Z, McGaughy V, Fisher L, Hickey WF, Basso DM (2002) The neuropathological and behavioral consequences of intraspinal microglial/macrophage activation. J Neuropathol Exp Neurol 61:623-633.

Popovich PG, van Rooijen N, Hickey WF, Preidis G, McGaughy V (2003) Hematogenous macrophages express CD8 and distribute to regions of lesion cavitation after spinal cord injury. Exp Neurol 182:275-287.

Rapalino O, Lazarov-Spiegler O, Agranov E, Velan GJ, Yoles E, Fraidakis M, Solomon A, Gepstein R, Katz A, Belkin M, Hadani M, Schwartz M (1998) Implantation of stimulated homologous macrophages results in partial recovery of paraplegic rats. Nat Med 4:814-821.

Rolls A, Shechter R, London A, Ziv Y, Ronen A, Levy R, Schwartz M (2007) Toll-like receptors modulate adult hippocampal neurogenesis. Nat Cell Biol 9:1081-1088.

Savli H, Gulkac AD, Esen N (2004) The effect of stimulated microglia conditioned media on BDNF gene expression of striatal astrocytes: quantification by real-time PCR. Int J Neurosci 114:1601-1612.

Schonberg DL, Popovich PG, McTigue DM (2007) Oligodendrocyte generation is differentially influenced by Toll-like receptor (TLR) 2 and TLR4mediated intraspinal macrophage activation. J Neuropathol Exp Neurol 66:1124-1135.

Schwartz M, Lazarov-Spiegler O, Rapalino O, Agranov I, Velan G, Hadani M (1999) Potential repair of rat spinal cord injuries using stimulated homologous macrophages. Neurosurgery 44:1041-1045.

Sholl DA (1953) Dendritic organization in the neurons of the visual and motor cortices of the cat. J Anat 87:387-406.

Steinmetz MP, Horn KP, Tom VJ, Miller JH, Busch SA, Nair D, Silver DJ, Silver J (2005) Chronic enhancement of the intrinsic growth capacity of sensory neurons combined with the degradation of inhibitory proteoglycans allows functional regeneration of sensory axons through the dorsal root entry zone in the mammalian spinal cord. J Neurosci 25:8066-8076.

Stoll G, Jander S, Schroeter M (2002) Detrimental and beneficial effects of injury-induced inflammation and cytokine expression in the nervous system. Mol Cell Biol 513:87-113.

Tanga FY, Nutile-McMenemy N, Deleo JA (2005) The CNS role of Toll-like receptor 4 in innate neuroimmunity and painful neuropathy. Proc Natl Acad Sci U S A 102:5856-5861.

Termeer C, Benedix F, Sleeman J, Fieber C, Voith U, Ahrens T, Miyake K, Freudenberg M, Galanos C, Simon JC (2002) Oligosaccharides of Hyaluronan activate dendritic cells via Toll-like receptor 4. J Exp Med 195:99-111.

Umemura N, Saio M, Suwa T, Kitoh Y, Bai J, Nonaka K, Ouyang GF, Okada M, Balazs M, Adany R, Shibata T, Takami T (2008) Tumor-infiltrating myeloid-derived suppressor cells are pleiotropic-inflamed monocytes/ macrophages that bear M1- and M2-type characteristics. J Leukoc Biol 83:1136-1144.

Underhill DM (2003) Macrophage recognition of zymosan particles. J Endotoxin Res 9:176-180.

Vallieres N, Berard JL, David S, Lacroix S (2006) Systemic injections of lipopolysaccharide accelerates myelin phagocytosis during Wallerian degeneration in the injured mouse spinal cord. Glia 53:103-113.

van Rooijen N, Sanders A (1994) Liposome-mediated depletion of macrophages-mechanism of action, preparation of liposomes and applications. J Immunol Methods 174:83-93.

van Rooijen N, Vannieuwmegen R (1984) Elimination of phagocytic cells in the spleen after intravenous injection of liposome-encapsulated dichloromethylene diphosphonate-an enzyme-histochemical study. Cell Tissue Res 238:355-358.

Wu DS, Zhang Y, Bo XN, Huang WL, Xiao F, Zhang XY, Miao TZ, Magoulas C, Subang MC, Richardson PM (2007) Actions of neuropoietic cytokines and cyclic AMP in regenerative conditioning of rat primary sensory neurons. Exp Neurol 204:66-76.

Yin YQ, Cui Q, Li YM, Irwin N, Fischer D, Harvey AR, Benowitz LI (2003) Macrophage-derived factors stimulate optic nerve regeneration. J Neurosci 23:2284-2293.

Yin YQ, Henzl MT, Lorber B, Nakazawa T, Thomas TT, Jiang F, Langer R, Benowitz LI (2006) Oncomodulin is a macrophage-derived signal for axon regeneration in retinal ganglion cells. Nat Neurosci 9:843-852.

Yu M, Wang H, Ding A, Golenbock DT, Latz E, Czura CJ, Fenton MJ, Tracey KJ, Yang H (2006) HMGB1 signals through Toll-like receptor (TLR) 4 and TLR2. Shock 26:174-179.

Zekki H, Feinstein DL, Rivest S (2002) The clinical course of experimental autoimmune encephalomyelitis is associated with a profound and sustained transcriptional activation of the genes encoding Toll-like receptor 2 and CD14 in the mouse CNS. Brain Pathol 12:308-319.

Zhang Z, Schluesener HJ (2006) Mammalian Toll-like receptors: from endogenous ligands to tissue regeneration. Cell Mol Life Sci 63:2901-2907. 